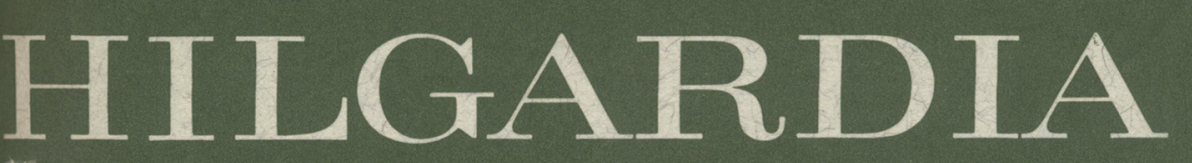

IOURNAL OF AGRICULTURAL SCIENCE PUBLISHED BY YHE CALIFORNIA AGRICULTURAL EXPERIMENT STATION

Volume 43, Number 4 May, 1975

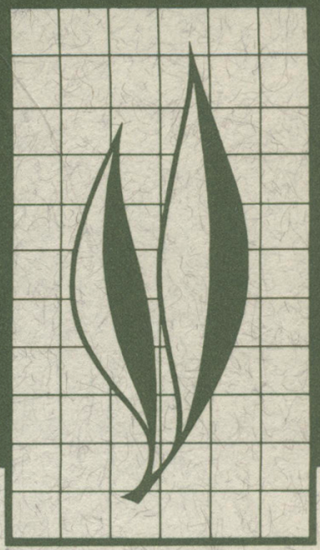

\title{
Phosphate Fluxes in the Soil-Plant System: A Computer Simulation
}

K. R. Helyar and D. N. Munns 


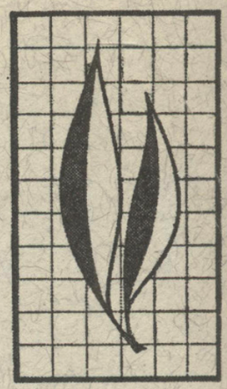

The kinetics of phosphate reaction in soil were simulated by means of the computer language IBM S/360 continuous systems modeling program (CSMP). The model includes parameters of intensity, capacity, and buffer capacity. Predicted changes in solution phosphate concentration following addition of various levels of calcium phosphate agreed with experimentally determined changes.

A separate model segment simulating uptake by plants was interfaced with the CSMP soil model. This segment uses standard numerical integration techniques, prepared in Fortran. It takes into account the convection and diffusion of phosphate to the root, the extension rate and radius of roots, length of root hairs, effect of solution phosphate concentration and root age on absorption, variation in slope of the sorption isotherm with phosphate concentration, and diurnal variation in transpiration rate.

Simulations have been run with several parameters varied over their natural range as observed in experiments with clover or recorded in the literature. The output of these simulations indicates that root extension, the soil's diffusion coefficient, and slope of the sorption isotherm have most influence, and that root hair length has less influence and root radius little. Convection contributed negligibly to computed uptake, but direct absorption from the root hair cylinder can be significant.

The most important assumptions which bear on the use of the model in its current state appear to be:

i) that within the root-hair cylinder neither diffusion nor desorption rates are limiting.

ii) that uptake constants for the individual root segment decline as the segment ages in a characteristic manner (about which little is known).

iii) that except by removing phosphate, the root does not significantly alter soil properties in the rhizosphere (including moisture content), so that diffusion coefficients and buffer capacities measured in bulk soil samples are applicable.

iv) that the contribution of mycorrhizal associations to uptake is not important.

\section{THE AUTHORS:}

K. R. Helyar was Research Assistant, Department of Soils and Plant Nutrition, University of California, Davis, California. Present address: Agricultural Research Centre, Wollongbar, New South Wales, 2480, Australia.

D. N. Munns is Associate Professor of Soil Science, Department of Soils and Plant Nutrition, University of California, Davis. 


\section{Phosphate Fluxes in the Soil-Plant System: A Computer Simulation ${ }^{1}$}

\section{INTRODUCTION}

The Chemistry of PHOSPHATE in soil is characterized by a state of thermodynamic disequilibrium. This is especially true when phosphate is being removed by plants and periodically added in the form of fertilizers and decaying plant residues. Such compounds as variscite, strengite, hydroxyapatite, and fluorapatite should be the stable end-products of phosphate reactions in soils, and in certain conditions crystalline minerals do form in soils (Lindsay and Moreno, 1960, Murrman and Peech, 1968). However, these minerals form slowly at normal soil phosphate concentrations and temperatures (Low and Black, 1950, Aslyng, 1954, Lindsay and Moreno, 1960, Larsen, 1967, Wilson, 1968). When a soluble phosphate is added to moist soil it is rapidly immobilized by adsorption reactions ( $\mathrm{Hsu}, 1964)$. Over longer periods of time, metastable crystalline phosphates may form, such as dicalcium phosphate, octacalcium phosphate, and taranakite-like minerals (Lindsay and Moreno, 1960). Isotopic dilution rate studies show that the lability of soil phosphate changes smoothly with time (Larsen, 1967, Wilson, 1968, Probert and Larsen, 1972). It follows from these considerations that a kinetic model of soil phosphate is more appropriate than a model based on postulations of thermodynamic equilibrium.

This paper presents a dynamic model which simulates changes in the soil solution phosphate concentration with time and the uptake of phosphate by plant roots. To solve the rate equations, the model uses the simulation language, IBM system S/360 Continuous System Modelling Program (CSMP), and standard numerical integration techniques prepared in Fortran.

\section{THEORETICAL}

Phosphate in the soil-plant system has been partitioned into five phases: plant phosphate, soil solution inorganic phosphate, fertilizer phosphate, adsorbed phosphate (rapidly reacting), and slowly-reacting phosphate. The broad concept of the model is illustrated in figure 1; soil organic phosphate, though shown in the figure, has not been included in the model at this stage.
Adsorbed phosphate. Phosphate adsorption occurs mainly on surfaces of soil minerals (Larsen, 1967, Jensen, 1971). There is probably a continum in terms of reaction rates between the various adsorbed and crystalline phosphates. Thus their distinction on a kinetic basis is difficult (Larsen, 1967) and must be largely arbitrary. In fact, the term "reaction rate" may be mis-

${ }^{1}$ Submitted for publication June 21, 1974. This work was supported in part by a grant from the National Science Foundation to the Computer Centre, University of California, Davis. 


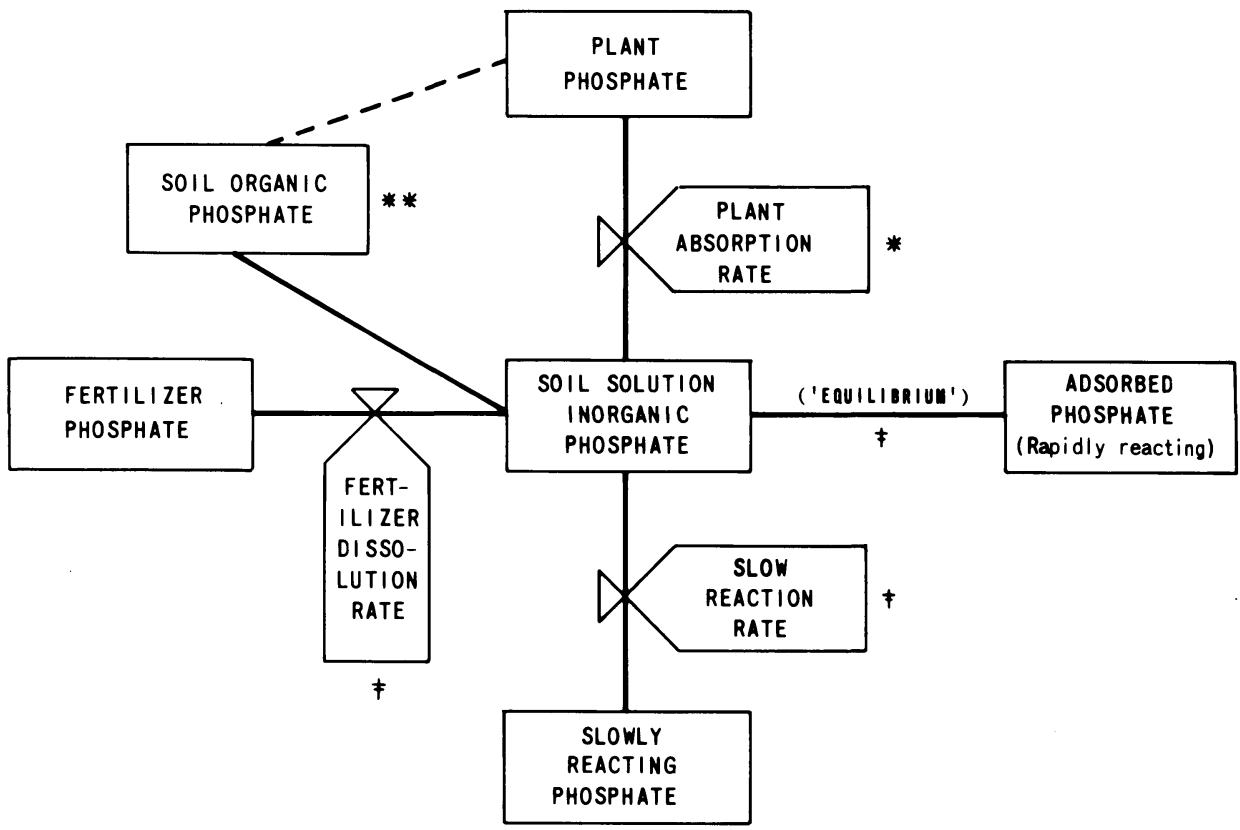

Fig. 1. Structure of the model partitioning soil and plant phosphate. ${ }^{*}=$ section modelled using the Fortran program; $\ddagger=$ sections modelled using the CSMP program; ${ }^{* *}=$ section not included.

leading as the over-all rate may be limited by diffusion to reaction sites rather than by reaction itself (Wilson, 1968).

For purposes of this model it has been convenient to define absorbed phosphate as a phase which exchanges with solution phosphate rapidly, within 24 hours. This eliminates the need to define a rate equation for the exchange between solution and adsorbed phases, since the exchange is adequately characterized by the sorption isotherm measured at 24 hours. Many effects of soil properties on solution phosphate can be included in the model by defining their effect on the isotherms. These properties include the content of sesquioxides (Swenson et al., 1949, Hau, 1964) the $\mathrm{pH}$ (Obihara and Russell, 1972), and the solution calcium concentration (Helyar et al., 1975).

The characteristics of phosphate adsorption and desorption isotherms have received extensive study (Beckett and White, 1964, Ozanne and Shaw, 1967, Kafkafi et al., 1967, Fox and Kamprath,
1970, Gunary, 1970). As there is little evidence that the more fundamentally derived Langmuir isotherm applies generally to soils (Gunary, 1970), the adapted function proposed by Gunary has been used in this model. The equation is:

$$
\frac{1}{X}=B+\frac{A}{C}+\sqrt{\frac{D}{C}}
$$

where $X=$ adsorbed phosphate ( $\mu$ moles $/ \mathrm{cm}^{3}$ soil $)$; $C=$ solution phosphate concentration ( $\mu \mathrm{moles} / \mathrm{ml})$; and $A, B$, and $D$ are arbitrary constants, found by fitting experimental data to the equation by the least-squares technique.

Slowly reacting soil phosphate. After addition of soluble phosphate to a soil or soil suspension, the rapid adsorption phase is followed usually by a continuing, slow, concentration-dependent immobilization reaction (Larsen, 1967, Wilson, 1968). The slowly reacting phosphate may also be mobilized to some degree when soil solution con- 
centrations are lowered by plant growth (Larsen, 1967, Probert, 1972).

In this simulation, the slow removal of phosphate from the soil solution and adsorbed phases has been characterized by a simple nth order equation, chosen from several equations discussed by Probert and Larsen (1972):

$$
-\frac{d X}{d t}=k_{1} X^{n}
$$

When integrated from $t_{o}$ to $t$ and $X_{o}$ to $X$, this becomes

$$
[X]^{-(n-1)}-\left[X_{o}\right]^{-(n-1)}=(n-1) k_{1} t
$$

Both $n$ and $k_{1}$ can be evaluated by the technique described by Frost and Pearson (1961), using values of $X$ calculated from experimental values of $C$ determined at different times $(t)$.

The release of slowly reacting phosphate to solution has not been included in the model at this time. It is probably a function of the amount of slowly reacting phosphate present. A basis for modelling this release may comprise data on the release of phosphate to anion exchange resins, from soils containing different amounts of slowly reacting phosphate (Amer et al., 1955).

Fertilizer phosphate. At the current stage, only phosphate fertilizers thoroughly mixed with soil have been considered. To model the dissolution of such a fertilizer a first-order rate expression has been used:

$$
\frac{d F_{p}}{d t}=-k_{3} F_{p}
$$

Where $F_{p}=$ fertilizer phosphate ( $\mu$ moles $\mathrm{cm}^{-3}$ soil); $t=$ time (hours); and $k_{3}=$ rate constant $\left(\right.$ hours ${ }^{-1}$ ).

The consideration of heterogenous distribution of fertilizer in a soil, such as with superphosphate granules, would require a more sophisticated treatment involving both dissolution rate of the pellet and diffusion on spherical coordinates from the pellet.
Phosphate uptake by plant roots. In recent years, two major reviews (Olsen and Kemper, 1967, Barley, 1970), and many individual papers (see above reviews and Brewster and Tinker, 1972, Bar-Yosef et al., 1972), have presented various models of uptake of a number of nutrients from soil by roots.

The principles involved in the diffusion and convection of nutrients from soil to roots and uptake by the roots are similar for all nutrients. For a nutrient with no significant diffusion within the adsorbed fraction, the equation given by Olsen and Kemper (1967) accounts for radial diffusion and convection:

$$
\frac{\partial c}{\partial t}=\frac{D_{p}}{(b+\theta)}\left\{\frac{\partial^{2} C}{\partial r^{2}}+\left(1-\frac{W}{2 \pi D_{p}}\right) \frac{1}{r} \frac{\partial C}{\partial r}\right\}
$$

where $C=$ nutrient concentration in solution ( $\mu$ moles $/ \mathrm{ml}) ; t=$ time (hours); $D_{p}=$ the porous system diffusion coefficient in the absence of an adsorbed diffusable fraction $\left(\mathrm{cm}^{2} \mathrm{hr}^{-1}\right) ; b=$ the slope of the sorption isotherm $=d X / d C=$ $f(C) ; \theta=$ volumetric moisture content $\left(\mathrm{cm}^{3} / \mathrm{cm}^{3}\right) ; \quad W=$ rate of convective movement of solution to the root $\left(\mathrm{cm}^{3}\right.$ (cm root) $)^{-1} \mathrm{hr}^{-1}$ ), $W$ being negative since the flow is in the direction of decreasing $r ; \quad V=W / 2 \pi r \theta=$ velocity of solution $\left(\mathrm{cm} \mathrm{hr}^{-1}\right)$.

The detailed derivation of this form of the equation is given in appendix 1 . $D_{p}=D\left(L / L_{e}\right)^{2} \theta \propto \gamma$, where $D$ is the diffusion coefficient of the subject ion in water, $L$ is the macroscopic distance between two points, $L_{e}$ is the actual path ions must pass through, $\theta$ is the moisture content, $\propto$ is the relative fluidity of water, and $\gamma$ is a factor for restriction of anion movement through small pores due to negative adsorption.

Equation 5 is solved in this model by a numerical technique which allows solution for a wide range of boundary conditions. Available analytical solutions require boundary conditions which are too restrictive to be realistic (Olsen 
and Kemper, 1967). This model includes the following non-linear conditions, which cannot be combined in an analytically solvable form of the general equation:

1. The soil-solution phosphate concentration away from the root at $r=r_{k}$ is a non-linear function of time as dictated by the CSMP simulation program.

2. The adsorption isotherm is nonlinear, so $b$ is a function of $C$.

3. At the root boundary the plant absorption rate is a nonlinear function of $C$, following the MichaelisMenten equation (Epstein and Hagen, 1952). The maximum uptake rate in this equation has also been made a function of root age, decreasing to zero at 10 days, and is expressed in terms of root length rather than surface area.

4. Within the root-hair cylinder, diffusion has been considered nonlimiting to phosphate transport. Thus the root-hair cylinder is treated as a reservoir into which phosphate moves by diffusion and convection, and from which the plant absorbs phosphate.

The fourth assumption is justified by the shortness of diffusion paths within the root-hair cylinder. The maximum diffusion path from soil within the cylinder to the tips of the root-hairs is about $60 \mu$ for a root of radius $0.015 \mathrm{~cm}$ with 1500 roothairs, of length $0.01 \mathrm{~cm}$ and diameter $10 \mu$, per cm root. These dimen- sions were typical of young subterranean clover roots removed from soils (unpublished data), though other species such as wheat may have longer and fewer root-hairs (Lewis and Quirk, 1967). Further, root exudates may increase the diffusion coefficient in this region. Lastly, from measured transpiration rates and root lengths of subterranean clover, it may be calculated that the water velocity in the root-hair zone varies up to $15 \mu \mathrm{min}^{-1}$, for transpiration rates up to $0.0024 \mathrm{ml}$ (cm root) $)^{-1}$ $\mathrm{hr}^{-1}$.

(Additional assumptions are that the diffusion coefficient $\left(D_{p}\right)$ is unaffected by hydrodynamic dispersion (Olsen and Kemper, 1967), that desorption rates are non-limiting, and that moisture content is constant at all values of $r$ ).

Equation (5) can be re-written in a simpler form as

$$
\frac{\partial C}{\partial t}=D_{a}\left\{\frac{\partial^{2} C}{\partial r^{2}}+P \frac{\partial C}{\partial r}\right\}
$$

where $D a=D p /(b+\theta)=$ the apparent diffusion coefficient

$$
\text { and } P=\frac{D_{p}}{(b+\theta)}\left(1-\frac{W}{2 \pi D_{p}}\right) \frac{1}{r}
$$

Using the Crank-Nicolson finite difference method (Crank, 1956) to approximate the first and second derivatives at a given radius $\left(r_{m}\right)$, and time $(t+1 / 2 \triangle t)$ for the interval $t$ to $(t+$ $\Delta t):$

$$
\frac{\Delta C}{\Delta r}=\frac{\left(C_{m+1}-C_{m-1}+C_{m+1}^{+}-C_{m-1}^{+}\right)}{4 \Delta r}
$$

and $\frac{\triangle^{2} C}{\Delta r^{2}}=\frac{\left(C_{m+1}-2 C_{m}+C_{m-1}+C_{m+1}^{+}-2 C_{m}^{+}+C_{m-1}^{+}\right)}{2(\Delta r)^{2}}$

In equation (10), $C$ and $C^{+}$are the soilsolution phosphate concentrations at time $t$ and $t+\Delta t$ respectively. The sub- scripts $(m),(m+1)$ and $(m-1)$ refer to the number of radial increments $(\Delta r)$ from the tip of the root-hairs; $m$ varying 
from 1 at $r=r_{1}$, at the root, to $k$ at $r=r_{k}$. The value of $k$ is automatically determined during program execution so that $C^{+}{ }_{k}=0.99 \times C o$. If a = root radius $(\mathrm{cm})$, and $r h=$ length of root-hairs (cm), $r_{1}=a+r h$; and $r_{m}=r_{1}+m(\triangle r)$.

Now combining (6), (9), and (10) and expressing (6) in finite difference form:

$$
\begin{aligned}
C_{m}^{+}=C_{m}+ & \frac{\Delta t}{2 \Delta r}\left\{\frac{D a}{r}\left[C_{m+1}+C_{m+1}^{+}-2\left(C_{m}+C_{m}^{+}\right)+C_{m-1}+C_{m-1}^{+}\right]\right. \\
& \left.+\frac{P}{2}\left[C_{m+1}+C_{m+1}^{+}-C_{m-1}-C_{m-1}^{+}\right]\right\}
\end{aligned}
$$

The boundary conditions at $r=r_{1}+$ $k(\triangle r)$, are given by:

$C_{o}=f$ (time), determined by the CSMP model, and

$$
C^{+}{ }_{m=} k_{+1}=C^{+}{ }_{m=k}+\left[\left(C_{o}-C^{+}{ }_{m=k}\right) / 10\right]
$$

Thus the concentration gradient is extrapolated linearly to $C_{o}$ over the distance $10(\triangle \mathrm{r})$ from $r_{m=k}$.

At the root surface, phosphate concentration is controlled by the fluxes of phosphate into and out of the root-hair cylinder. Thus $P_{t^{+}}=P_{t}-\Delta P_{1}+\Delta P_{2}$, where $P_{1}^{+}=$adsorbed + solution phosphate in the root-hair cylinder ( $\mu$ moles /cm root); $\triangle P_{1}=$ phosphate uptake ( $\mu$ moles $/ \mathrm{cm}$ root $/ \Delta t$ ) ; and $\Delta P_{2}=$ diffusion and convection to the root ( $\mu$ moles $/ \mathrm{cm} / \triangle t)$. Then $X^{+}=P_{t^{+}}-\left(C_{1} \times \theta \times\right.$ volume root-hair cylinder $)=\mu$ moles $/ \mathrm{cm}$ root.

Now $C^{+}(\mu$ moles $/ \mathrm{ml})$ is found as a function of $\bar{X}^{+}$, by expressing the adsorption isotherm (1) in the quadratic form, substituting $X^{+}\left(\mu \mathrm{moles} / \mathrm{cm}^{-\mathrm{s}}\right.$ soil),

$$
C^{2}\left(\frac{1}{X^{+}}+B\right)^{2}-C\left(D^{2}+2 \frac{A}{X^{+}}-2 A B\right)+A^{2}=0
$$

and solving for the appropriate root.

Diffusion and convection of phosphate into the root-hair cylinder per $\mathrm{cm}$ of root is given by

$\Delta P_{2}=\left\{2 \pi r{ }_{1} D_{p}\left(\frac{\Delta C}{\Delta^{r_{1}}}\right)-W C_{1}\right\} \Delta t$

Where

$$
\left(\frac{\Delta C}{\Delta r}\right)_{1}=\left(C_{2}-C_{1}+C_{2}^{+}-C_{1}^{+}\right) / 2 \Delta r .
$$

Plant uptake is given by

$$
\Delta P_{1}=\left\{V_{m} C /(p+C)\right\} \Delta t
$$

where $p=$ constant; $\nabla_{m}=$ maximum uptake rate constant ( $\mu$ moles (cm root) $)^{-1}$ $\left.\mathrm{hr}^{-1}\right)$; and $C=\left(\mathrm{C}_{1}+C_{1}^{+}\right) / 2=$ the average phosphate concentration in the root-hair cylinder for the period $t$ to $(t+\Delta t)$.

The values of $V_{m}$ and $p$ in equation (15) were determined from the data of Loneragan and Asher (1967) for subterranean clover, assuming a fresh weight to root-length correlation for young subterranean clover plants determined in this laboratory $(1400 \mathrm{~cm} / \mathrm{g}$ fresh weight). The estimate of $\nabla_{m}$ was varied with root age according to the function shown in figure 2. The form of this function was based on Rovira and Bowen's (1968) data on variation of phosphate uptake along wheat roots. The range of root diameter and roothair length used in the simulations was typical of our measurements of fine roots of soil-grown subterranean clover (cultivar Mt. Barker). 


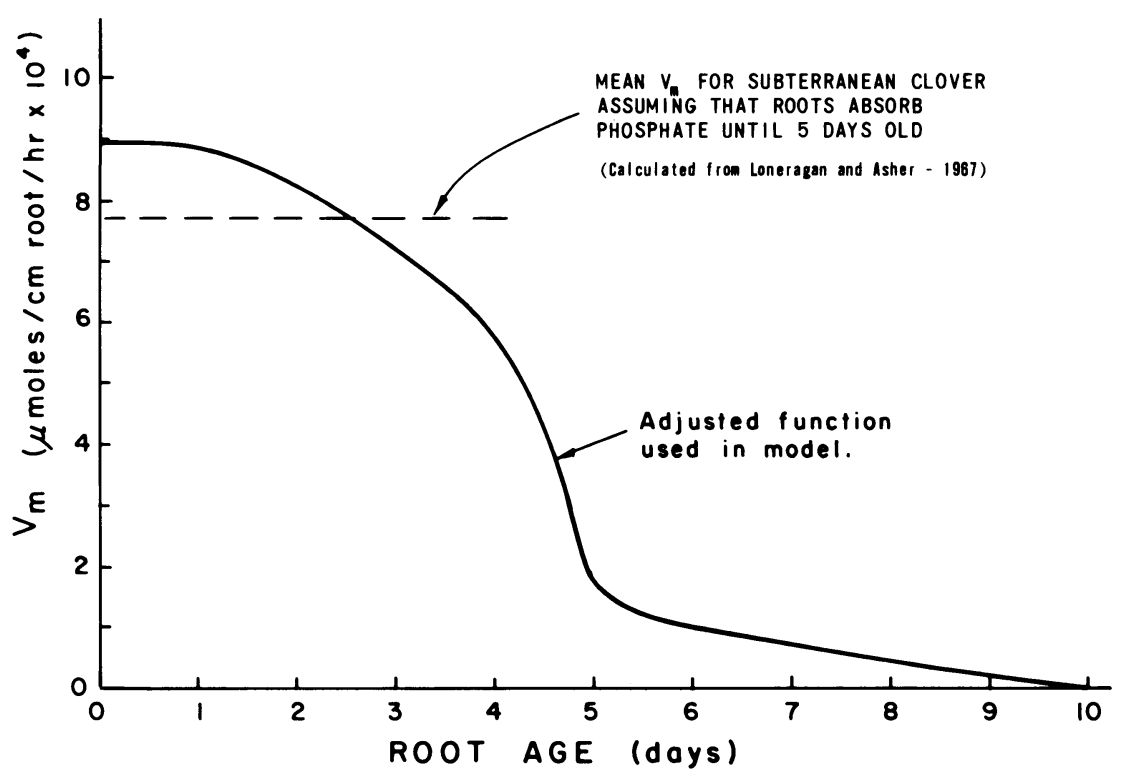

Fig. 2. Maximum uptake rate constant as a function of root age.

At the beginning of a set of calculations, before any uptake by the plant root, $C_{m}$ is known and $C_{m}{ }^{+}$and $C_{m}^{-}$are assumed equal to $C_{m}$. After the initial iteration, $C_{m}^{-}$and $C_{m}$ are known and $\mathrm{C}_{m}{ }^{+}$is estimated using a linear extrapolation,

$$
C_{m}{ }^{+}=2 C_{m}-C_{m}^{-}
$$

To calculate a new value of $C_{m}{ }^{+}$the finite difference equation (12) is calculated repeatedly. At each iteration all values of $C_{m}$ are calculated, $m=1$ to $m=k$, the most recent values of $C_{m}{ }^{-}$ and $C_{m}$ being used to calculate $C_{m}{ }^{+}$. Once all values of $\mathrm{C}_{m}{ }^{+}$have been calculated to a tolerance of $C_{m}{ }^{+} \pm 0.05 \mu M P$, then time is incremented and the next set of calculations begun. The absorption of phosphorus by each day's root growth is followed for the next 10 days, the values of $V_{m}$ being adjusted hourly, and of $C_{o}$ daily.

\section{RESULTS OF THE SIMULATION STUDIES}

\section{The CSMP model of phosphate fluxes between soil phases}

Figure 3 compares typical results of this model with experimental data from a soil of the Red Bluff series, 0-10 cm. The soil was prepared by sieving it airdry through a 0.5 -cm sieve, mixing, and weighing portions into individual pots. The weighed, finely ground amounts of $\mathrm{Ca}\left(\mathrm{H}_{2} \mathrm{PO}_{4}\right)_{2} \cdot \mathrm{H}_{2} \mathrm{O}$ were then applied to each pot and mixed with the soil. For the two treatments, 8.3 and $36.2 \mu$ moles $\mathrm{P}$ per $\mathrm{cm}^{3}$ soil were applied to 1-kg lots of soil having a bulk density of 1.12 . The pots of soil were subsequently maintained at a moisture suction of approximately 0.33 bars, and a temperature of $26^{\circ} \mathrm{C}$. At the times indicated, samples of the soil solution were extracted, using a centrifuge at a relative centrifugal force of 12,000 , and analyzed by the technique described by Helyar and Brown (1975).

The simulated trends in soil-solution phosphate concentration adequately described the observed trends for the two 


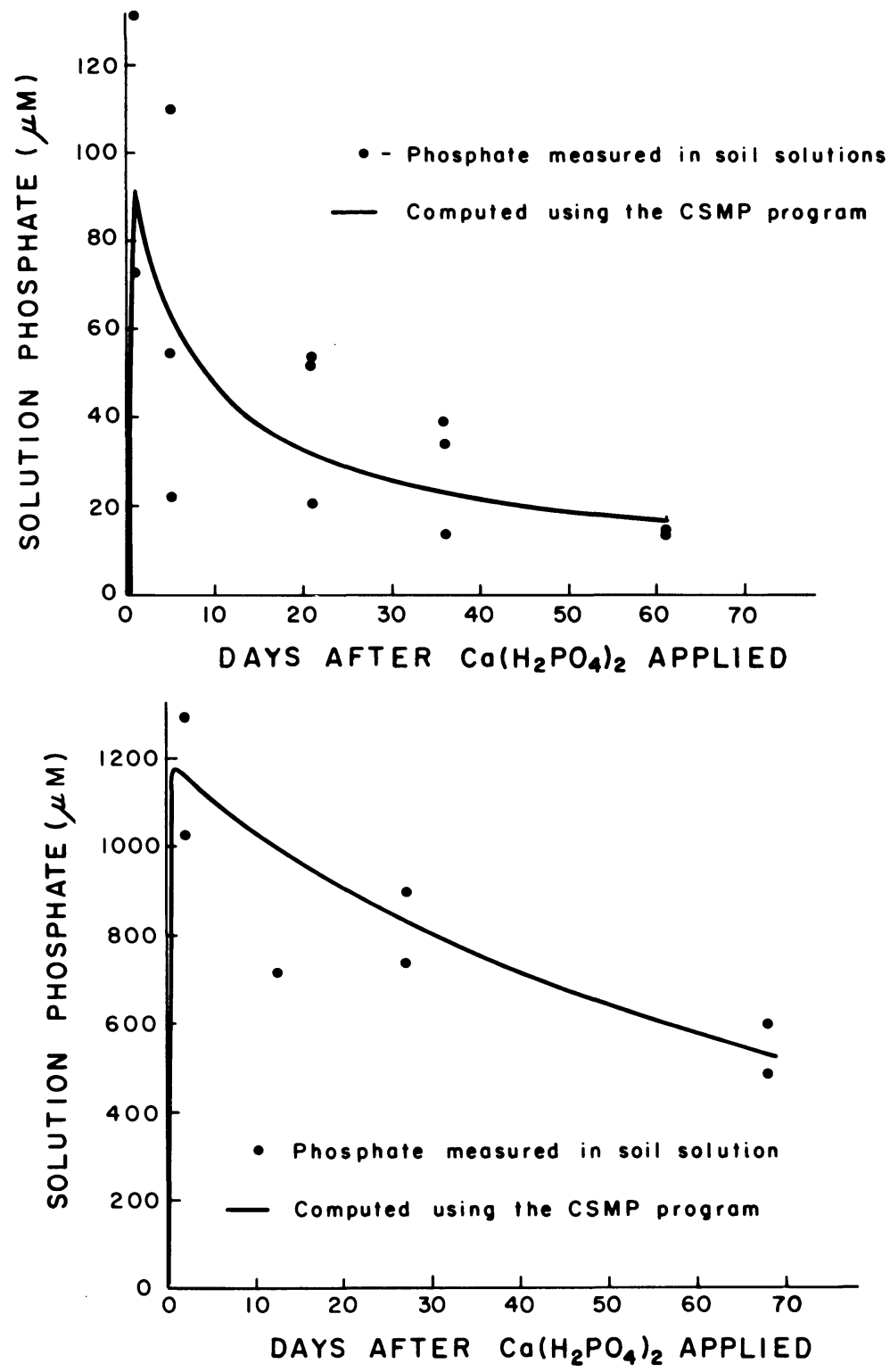

Fig. 3. Effects of time after applying $\mathrm{Ca}\left(\mathrm{H}_{2} \mathrm{PO}_{4}\right)_{2}$ on soil solution phosphate concentration in Red Bluff soil. Upper: $8.3 \mu$ moles $\mathrm{P}$ added per $\mathrm{cm}^{3}$ soil. Lower: $36.2 \mu$ moles $\mathrm{P}$ added per $\mathrm{cm}^{3}$ soil.

fertilizer levels shown in figure 3. The large variations in the soil solution phosphate concentrations, especially for the shorter times, make more accurate simulation pointless. The reason for the observed variability in phosphate concentration at a given time is not known.

\section{The plant uptake model}

Stability and convergence characteristics. A stable convergent solution resulted if a radius increment of $0.002 \mathrm{~cm}$ was used, and if the stability criterion for equation (6), $D_{a} \cdot \triangle t /(\triangle r)^{2}$ (Richmeyer, 1957), was set equal to 0.5 . The 


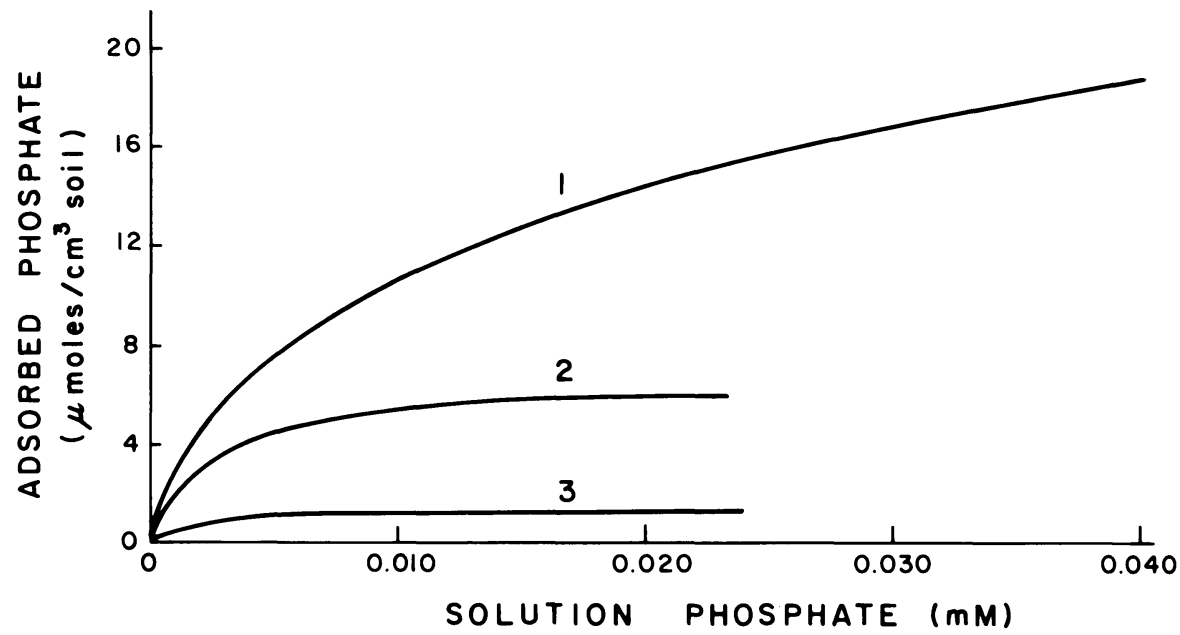

Fig. 4. Phosphate adsorption isotherms fitted to equation (1). Constants A, B, and D, respectively in text equation (1) were: isotherm $1(0.000165,0.0220,0.00551)$; isotherm $2(0.000316$, $0.149,0.00120)$; isotherm $3(0.00167,0.783,-0.0145)$.

TABLE 1

PHOSPHATE UPTAKE AS AFFECTED BY SOIL SOLUTION CONCENTRATION (CO), ADSORBED PHOSPHATE (X), AND THE ADSORPTION ISOTHERM

\begin{tabular}{c|c|c|c|c}
\hline \hline \multirow{2}{*}{$\begin{array}{c}\text { Soll solution } \\
\text { concentration }\end{array}$} & \multicolumn{2}{|c}{ Isotherm 1 (b, large** } & \multicolumn{2}{c}{ Isotherm 2 (b, small)* } \\
\cline { 2 - 5 } & $\begin{array}{c}\text { Adsorbed } \\
\text { phosphate }\end{array}$ & $\begin{array}{c}\text { Phosphate } \\
\text { uptake }\end{array}$ & $\begin{array}{c}\text { Adsorbed } \\
\text { phosphate }\end{array}$ & $\begin{array}{c}\text { Phosphate } \\
\text { uptake }\end{array}$ \\
\hline$\mu \mathrm{M}$ & $\mu \mathrm{mol} / \mathrm{cm}^{3}$ & $\mu \mathrm{mol} / \mathrm{cm} / 10$ days & $\mu \mathrm{mol} / \mathrm{cm}^{3}$ & $\mu \mathrm{mol} / \mathrm{cm} / 10$ days \\
1 & 2.8 & 0.0066 & 2.0 & 0.0047 \\
5 & 7.5 & 0.0174 & 4.4 & 0.0115 \\
10 & 10.7 & 0.0265 & 5.2 & 0.0158 \\
20 & 14.4 & 0.0400 & 5.8 & 0.0210 \\
\hline
\end{tabular}

" Isotherms of figure 4.

time variable $(\Delta t)$ was determined during program execution using this criterion. At higher values of $\Delta r$ the solution was not convergent, and at higher values of $D a\left(\frac{\Delta r^{2}}{\Delta t}\right)$ more iterations became necessary. The computations became unstable as $D a\left(\frac{\Delta r^{2}}{\Delta t}\right)$ approached 1. At low values of $b, \Delta r$ values up to 0.006 could be used to reduce computation time. The incurred errors of 2 to 3 per cent were considered not significant. Bimulation studies. Table 1 shows the results of simulation studies in which $C_{o}$ was held constant with time but varied for different runs and for different adsorption isotherms (fig. 4). Figures 5 to 12 show the effects of varying $D_{p}$, the root radius, the root-hair length and the adsorption isotherms. During the simulations the value of $C_{o}$ was reduced daily (fig. 5), simulating the trend shown in figure 3 . Convection of water and phosphate to the root was zero.

The diffusion coefficient $\left(D_{p}\right)$ was varied from $0.02 \mathrm{~cm}^{2} \mathrm{hr}^{-1}$, a near-maximal value for unsaturated soils, to 0.001 $\mathrm{cm}^{2} \mathrm{hr}^{-1}$, a value representative of unsaturated soils of coarser texture than clays. At $\mathrm{pH}$ values above 7.0 where $\mathrm{HPO}_{4}=$ is the dominant phosphate ion, values between 0.0001 and 0.008 would 


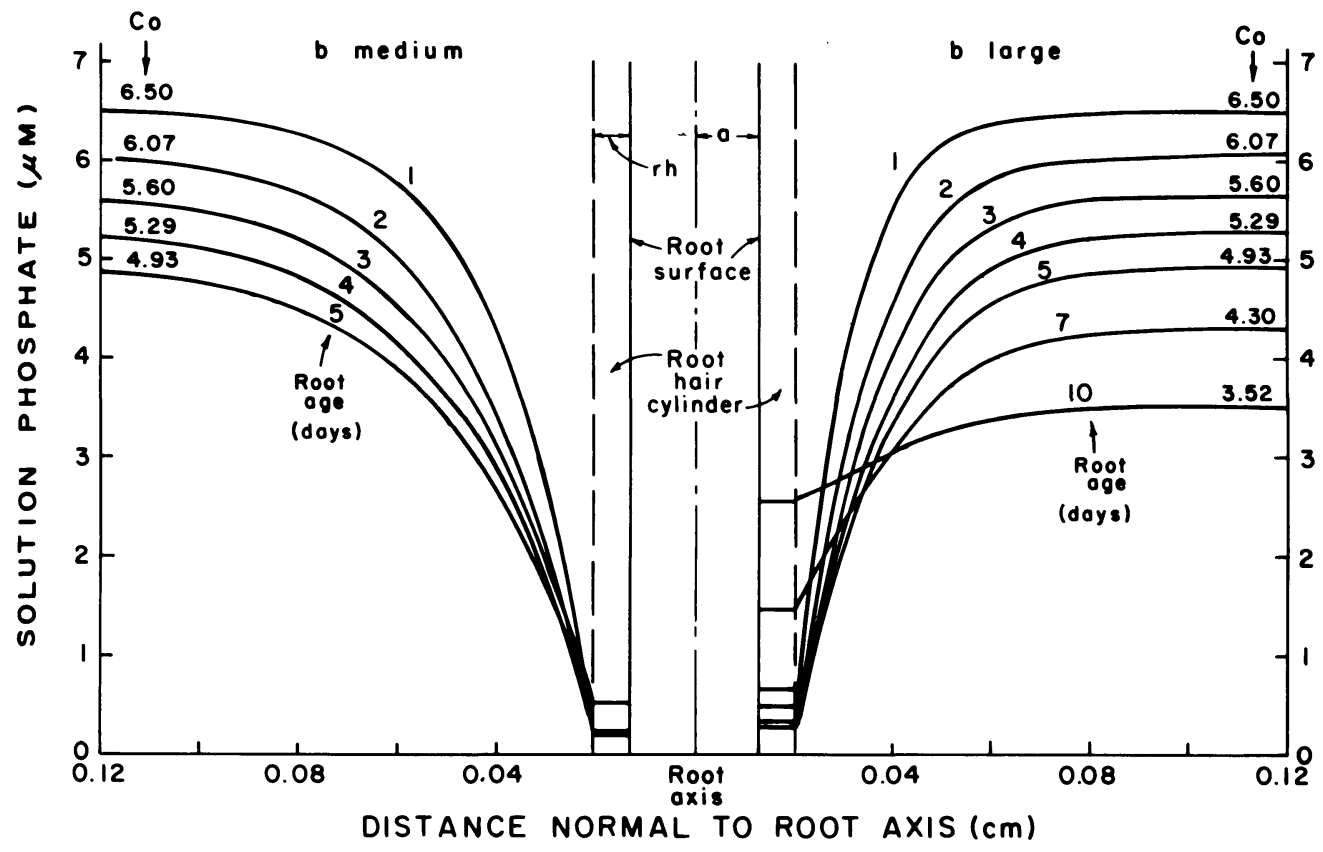

Fig. 5. Phosphate concentration gradients near the root for different adsorption isotherms and days of absorption ( $\mathrm{Dp}=0.005, \mathrm{~b}$ medium and large represents isotherms 2 and 1 respectively, $\mathrm{rh}=0.0075 \mathrm{~cm}, \mathrm{a}=0.013 \mathrm{~cm}, \mathrm{Vm}=0.00075 \mu$ moles $\mathrm{cm}^{-1} \mathrm{hr}{ }^{-1}$, and $\mathrm{P}=0.67 \mu$ moles $1^{-1} . \mathrm{C}_{o}$ decreased daily as shown on the figure).

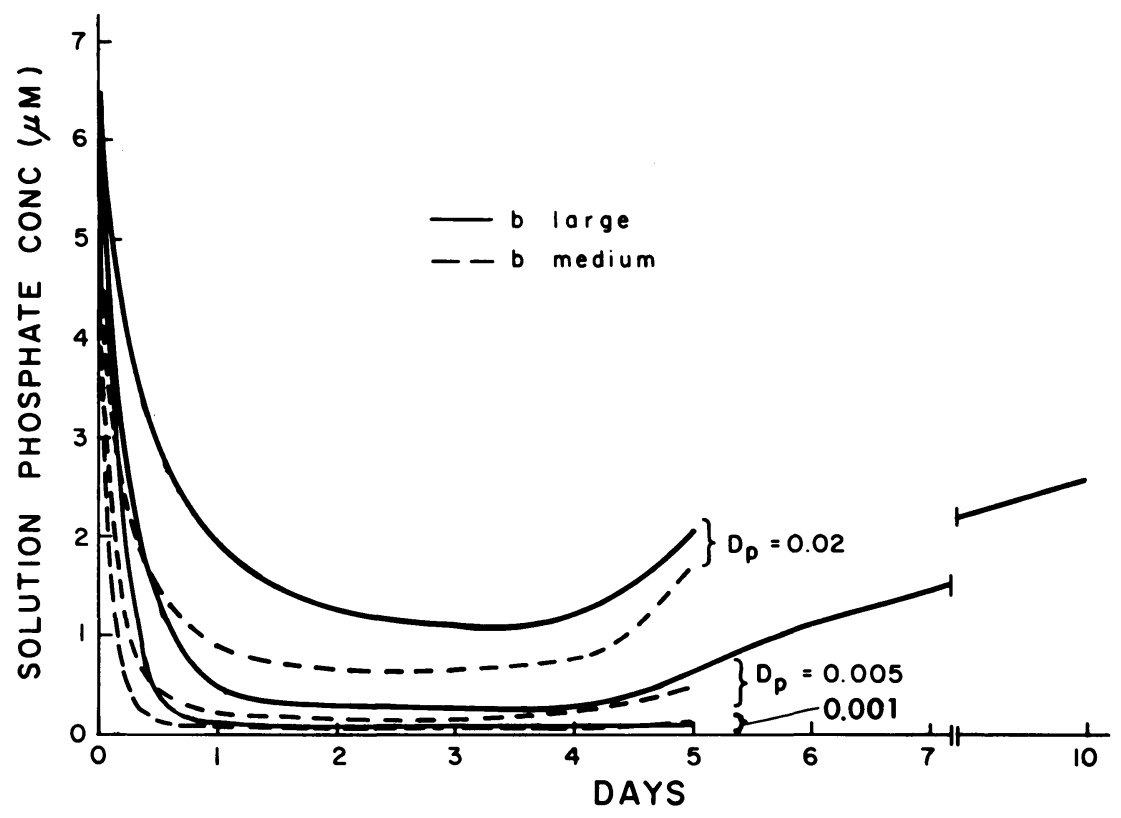

Fig. 6. Effects of different diffusion coefficients and adsorption isotherms on phosphate concentration at root surface (other conditions as for figure 5). 


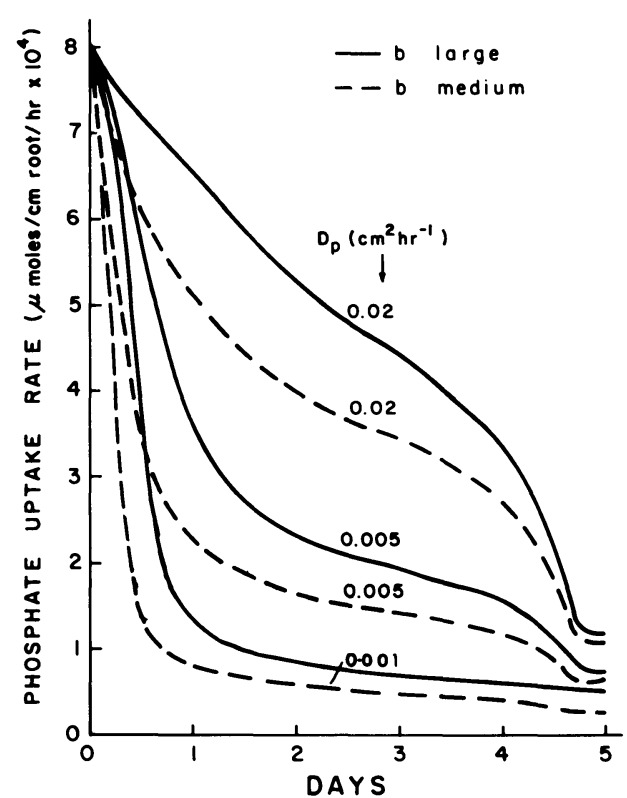

Fig. 7. Effects of different adsorption isotherms and diffusion coefficients on phosphate uptake (other conditions as for figure 5).

be more appropriate (Olsen et al., 1965, Drew and Nye, 1970, Barley, 1970).

The solution concentration in the root-hair cylinder $\left(C_{1}\right)$ decreased rapidly in the first day and then remained relatively steady until day 5 when diffusion became greater than the plant uptake rate (figs. 5, 6). The decrease of $C_{1}$ was greater where $D_{p}$ and the adsorption isotherm slope $(b)$ were small. The simulation was continued for 10 days in the case of isotherm 1 (fig. 4) and the $D_{p}$ value of 0.005 . After 5 days the uptake rate had decreased to near zero (fig. 7) because of the reduction of $V_{m}$ with root age (fig. 2). The linear rate of increase of $C_{1}$ with time in this period (fig. 6) is presumably due to compensation between a decreased diffusion rate with time and a decreased adsorption isotherm slope as $C_{1}$ increased. This rate of increase would be a consideration if the model was extended to include interactions between roots and the exploitation of depleted areas by new roots.

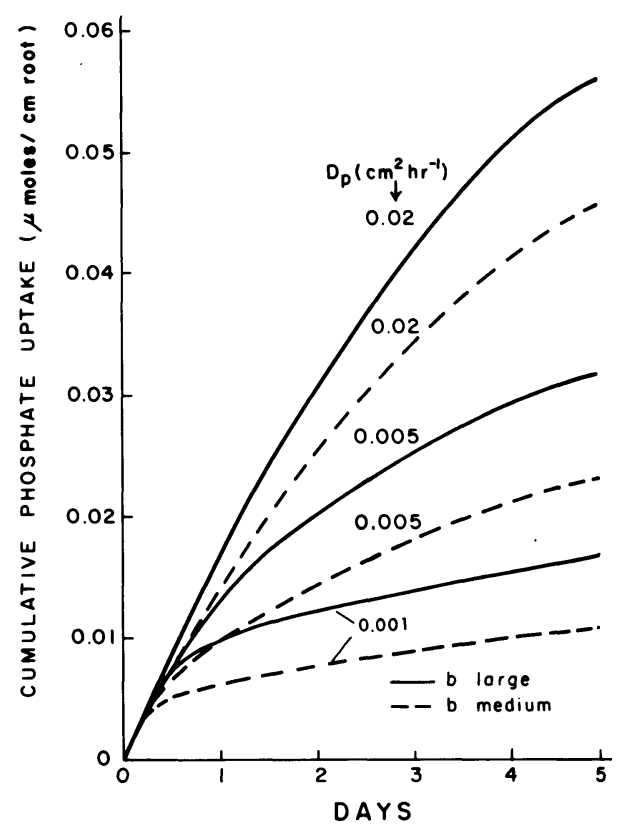

Fig. 8. Effects of different adsorption isotherms and diffusion coefficients on cumulative phosphate uptake (other conditions as for fig. ure 5).

The slope of the concentration gradient near the root determines the rate of diffusion into the root-hair cylinder and, thus, the supply of phosphate to the plant. The slope of the concentration gradient becomes smaller with time and is smaller the lower the slope of the adsorption isotherm (fig. 5). Figures 7 and 8 illustrate these influences on uptake rate and cumulative uptake. Increasing the isotherm slope increased uptake by 24,38 , and 57 per cent for $D_{p}=0.02$, 0.005 and 0.001 , respectively. However, changing $D_{p}$ from 0.001 to 0.02 increased uptake more, by 3.3 and 4.2 times for isotherms 1 and 2, respectively.

Effects of varying $V_{m}$ and $p$ were studied at a solution concentration of $10 \mu \mathrm{M} P$. Other conditions were: adsorption isotherm 1 (fig. 4 ), $D_{p}=0.001$, $\theta=0.2, r h=0.01$, and $a=0.1 . V_{m}$ was varied above and below the value of $0.00075 \mu$ moles $\mathrm{cm}^{-1} \mathrm{hr}^{-1}$ calculated from Loneragan and Asher's (1967) data for 


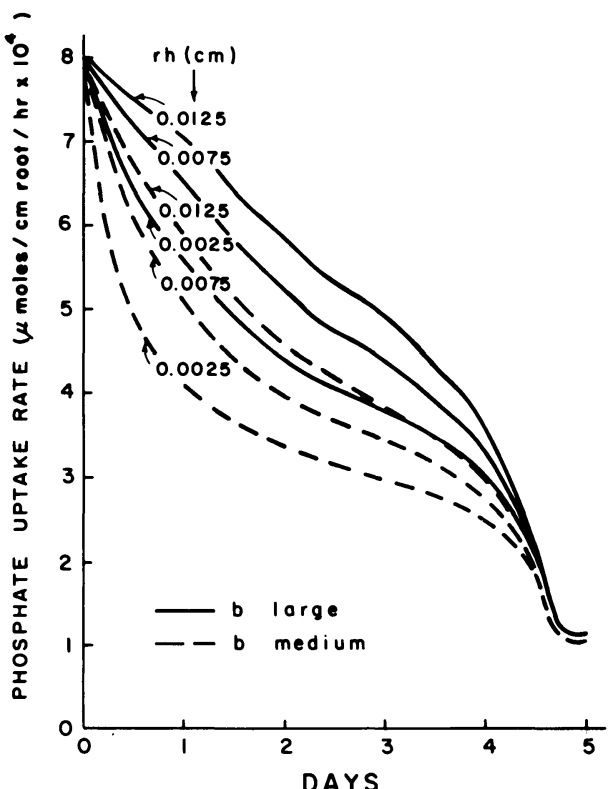

Fig. 9. Effects of root-hair length and adsorption isotherms on phosphate uptake rate $\left(D_{p}=0.02 \mathrm{~cm}^{2} \mathrm{hr}^{-1}\right)$; other conditions as for figure 5 .

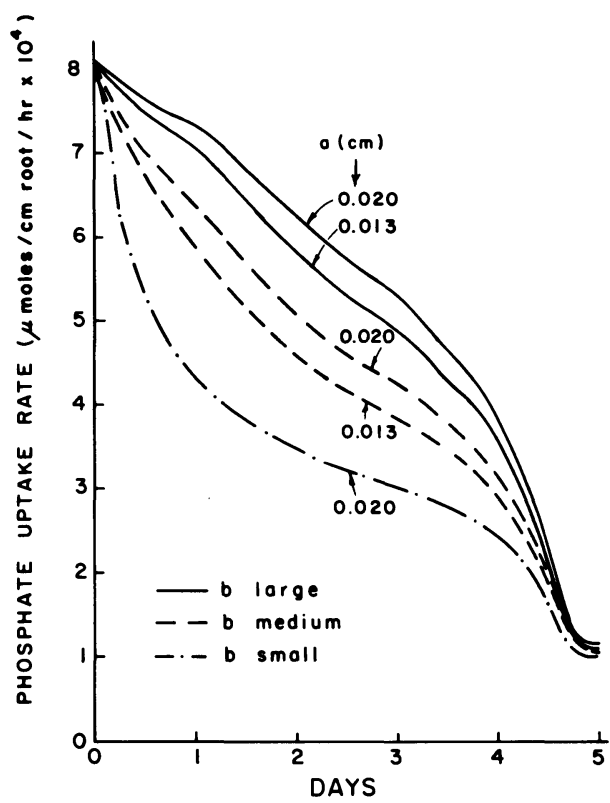

Fig. 11. Effects of root radius and adsorption isotherms on phosphate uptake ( $\mathrm{rh}=0.0125$ $\mathrm{cm}, \mathrm{D}_{\mathrm{p}}=0.02 \mathrm{~cm}^{2} \mathrm{hr}^{-1}, \mathrm{~b}$ large, medium and small represent isotherms 1,2 , and 3 respectively) (other conditions as for figure 5).

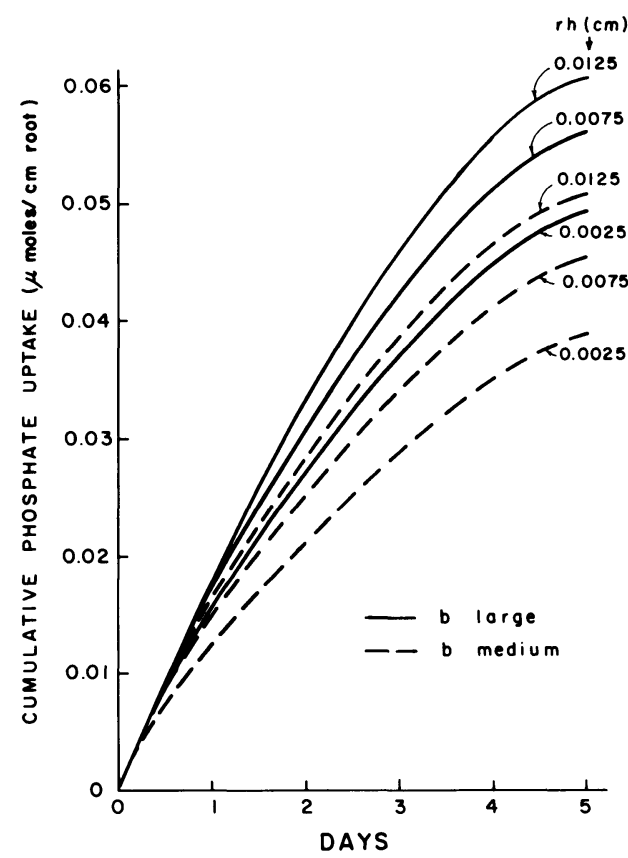

Fig. 10. Effects of root-hair length and adsorption isotherms on cumulative phosphate uptake (other conditions as for figure 9 ).

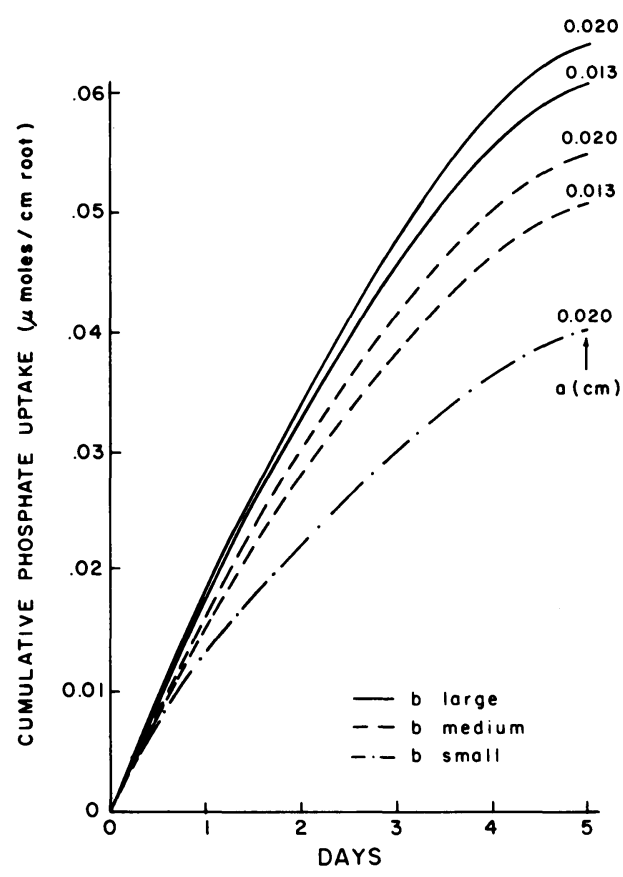

Fig. 12. Effects of root radius and adsorption isotherms on cumulative phosphate uptake (other conditions as for figure 11). 
Trifolium subterraneum cultivar Mt. Barker. With $p$ held at 0.67 , increasing $V_{m}$ from 0.0002 to 0.0005 , to 0.001 , and to 0.002 caused phosphate uptake to increase by successive increments of 34 , 4.7 and 4.5 per cent. With $V_{m}$ held at $0.00075 \mu$ mole $\mathrm{cm}^{-1} \mathrm{hr}^{-1}$, decreasing $p$ from 0.67 to 0.1 caused phosphate uptake to increase by 4 per cent.

Figures 9 to 12 show effects of roothair lengths and root diameter on up- take rate and on cumulative uptake. Increasing root-hair length, from 0.0025 to $0.0125 \mathrm{~cm}$ increased uptake by 22 and 30 per cent for the adsorption isotherms 1 and 2 respectively (figs. 9, 10). Changing the root radius, however, had less effect (figs. 11, 12). Increases in uptake of only 5 and 8 per cent for isotherms 1 and 2 , respectively, resulted when root radius increased from 0.013 to 0.020 $\mathrm{cm}$.

\section{DISCUSSION}

Much variation in phosphate availability among soils has in the past been attributed to variation in the intensity $\left(C_{o}\right)$, the capacity $(X)$ and the differential buffering capacity $(b)$ (Williams, 1962, Beckett and White, 1964). In this study these factors have marked effects on uptake, but additional factors have been included, viz. changes in $C_{o}$ with time, the diffusion coefficient in the absence of interaction $\left(D_{p}\right)$, root diameter, the length of the root hairs and the maximum uptake rate parameter of the plant and the way this changes with time.

The model has some similarities to the one used by Bar-Yosef et al., (1972), but their model differs in ignoring convection, root hairs, and time changes in external phosphate, and in defining the boundary condition at the root by setting uptake equal to influx, a condition which may be unrealistic and which can generate instability.

Changes of $C_{o}$ with time. The CSMP program has described the changes of $C_{o}$ with time reasonably accurately (fig. 3). This model takes into account not only the intensity, capacity and buffering capacity aspects of soil phosphate, but also the rate of immobilization of the rapidly reacting phosphate forms which constitute the capacity. At least in acid soils this immobilization may be an important cause of depletion of 'available' soil phosphate. Ability to predict its rate in different soils and conditions would improve the precision of fertilizer recommendations. Further, the information would be of use in assessing the value of soil $\mathrm{pH}$ amendment, and in deciding the relative merits of frequent small applications of phosphate fertilizers as against infrequent large applications.

Effects of intensity $\left(C_{o}\right)$, capacity $(X)$, diff erential buffering capacity $(b)$, and diff usion coefficient $\left(D_{p}\right)$. Increasing $C_{0}$ and $x$ increased the computed uptake of phosphate (table 1 ). At a given $C_{o}$ value the root absorbs more phosphate if $b$ is larger. However, more fertilizer may be required to support adequate levels of $C_{o}$ and rates of uptake for optimum growth of plants on soils with steep adsorption isotherms (large values of $b$ ).

Variation of $D_{p}$ caused large changes in phosphate uptake (fig. 8). The value of $D_{p}$ was found by Olsen et al. (1965) to vary from 0.0014 to $0.0056 \mathrm{~cm}^{2} \mathrm{hr}^{-1}$ in response to decreasing the soil moisture suction from 6 to 0.1 bar. Such changes are likely to be one of the main causes of decreased phosphate uptake at low moisture levels (Olsen et al., 1961), and the model predicts that this effect would also contribute to the reduced phosphate uptake.

Variation of the 'impedance factor' $\left((L / L e)^{2} \alpha \gamma \theta\right)$ at a constant moisture potential also influences $D_{p}$. At a moisture potential of 0.33 bars and $\mathrm{pH}$ of 
about 7.6, Olsen et al. (1965) found $D_{p}$ to vary from 0.0009 for a fine sandy loam to 0.003 for a clay. The $\mathrm{pH}$ is important because the $\mathrm{H}_{2} \mathrm{PO}_{4}{ }^{-}$ion has a larger diffusion coefficient in water $\left(0.032 \mathrm{~cm}^{2} \mathrm{hr}^{-1}\right)$ than the $\mathrm{HPO}_{4}=$ ion (0.018 $\mathrm{cm}^{2} \mathrm{hr}^{-1}$ ) (Lewis and Quirk, 1967). Drew and Nye (1970) estimated $D_{p}$ values of 0.0058 and 0.0038 for a sandy loam and a clay, respectively. They do not state the moisture potential or the soil $\mathrm{pH}$ values but indicate that $\mathrm{H}_{2} \mathrm{PO}_{4}^{-}$was the ion considered. Lewis and Quirk (1967) using soils with water-filled pores, varying in $\mathrm{pH}$ $\left(\mathrm{CaC1}_{2}\right)$ from 4.9 to 7.4 and in texture from sandy loam to clay, found a variation in $D_{p}$ from 0.003 to $0.01 \mathrm{~cm}^{2} \mathrm{hr}^{-1}$. Thus it appears that at a moisture tension of 0.33 bars $D_{p}$ could be expected to vary between soils over the range 0.001 to $0.01 \mathrm{~cm}^{2} \mathrm{hr}^{-1}$. These values have all been determined with soils whose macrostructure has been eliminated by sieving. In naturally-structured soils $D_{p}$ may be smaller, and the range of 0.0004 to 0.004 given by Barley (1970) may be more realistic. Large differences in phosphate uptake rates could be induced by such variation (fig. 8), thus indicating that the impedance factor at constant moisture potential is a significant variable, though less important than soil moisture content.

Effects of plant uptake parameters $V_{m}$ and $p$. Decrease of $p$, and increase of $V_{m}$ above about $0.0005 \mu$ moles $\mathrm{cm}^{-1} \mathrm{hr}^{-1}$, has little effect on phosphate uptake, at least for values of $C_{o}$ of $10 \mu \mathrm{M}$ or less. However, at higher concentrations of phosphate in the soil solution, higher values of $V_{m}$ would become influential. At concentrations of 100 to $1000 \mu \mathrm{M}$ (such as near fertilizer bands or granules), the high $V_{m}$ values of uptake mechanisms that operate only at high phosphate concentrations could enhance uptake.

Effects of root radius and root-hair length. According to the assumptions of this model, increases in the root radius or the root-hair length increase phosphate uptake in two ways. Firstly, the volume of the root-hair cylinder increases, thus increasing the buffering capacity of this reservoir into which phosphate is diffusing and from which the plant absorbs phosphate. Secondly, surface area of the root-hair cylinder increases, thus increasing the area across which diffusion may occur. This model predicts that changes in root-hair length are more significant than changes in root diameter. Both variables affect uptake enough to require their inclusion in the models as variables.

Nye (1966) also concluded that roothairs increase the plant's ability to absorb phosphate. His model was based on the assumption that root-hairs effectively increased root radius. Passioura (1963) treated the tips of the root-hairs as the effective surface for mass flow and diffusion. However, Kautsky et al. (1968) defined an 'equivalent cylinder' as the effective surface for mass flow and diffusion. The surface area of the equivalent cylinder was the same as the surface area of the root plus the surface area of the root-hairs. Their approach has the advantage of taking into account the number as well as the length of root-hairs. The radius of the equivalent cylinder is smaller than the root radius plus the root-hair length for the cases considered here. For example, a root with radius $0.013 \mathrm{~cm}$ and 1500 roothairs of length $0.075 \mathrm{~mm}$ and diameter $10 \mu$ per $\mathrm{cm}$ root, would have equivalent cylinder radius of $0.0184 \mathrm{~cm}$ but a root radius plus root-hair length of 0.0204 cm. Thus the assumption of Kautsky et al. would result in a lower estimate of the role of root-hairs, while the assumption used in this model results in a maximal estimate. Studies of the root geometry of subterranean clover, alfalfa, and barrel medic in this laboratory have shown the following variations for plants grown in soils treated with dif- 
ferent levels of phosphate and nitrogen: average root-hair lengths varied between 40 and $200 \mu$ : number of roothairs per $\mathrm{cm}$ root varied between 700 and 1500; and root-hair diameter was regular at about $10 \mu$. These lengths are shorter, and numbers greater, than observed on wheat by Lewis and Quirk (1967). If the model does overestimate the effect of root-hairs, the error will increase as the root-hair length is increased and as the number per $\mathrm{cm}$ root is decreased.

The role of convection. In greenhouse pot experiments with subterranean clover, root lengths and daily transpiration were measured. The maximum transpiration rate recorded on any day corresponded to $0.0025 \mathrm{ml}$ per $\mathrm{cm}$ root per hour ( $W=-0.0025$ ), assuming that the transpiration period was 9 hours and the total root length was active in water absorption. When this value of $W$ was included in the simulation, it made essentially no difference in uptake ( 0.7 per cent increase). (Adsorption isotherm 1 [fig. 4] was used, $D_{p}$ was set at $0.005, a$ at $0.013 \mathrm{~cm}$, and $r h$ at $0.0075 \mathrm{~cm}$.) The contribution of convection to phosphate uptake is not $-W C_{o}$, as was assumed by Barber (1962). The contribution due to convection is the convective flux of phosphate at the root surface $\left(-W C_{1}\right)$, plus the increased rate of diffusion due to the increase in the total diffuseable phosphate concentration at $r_{k}+10 \Delta r$ which arises from the convective flux $-W C_{o}$. The value of $-W C_{1}$ is rapidly reduced to a small figure after absorption has begun (fig. 6 ), and the percentage contribution of $-W C_{o}$ to the total diffuseable phosphate at $r_{k}+10 \Delta r$ will be small, especially if $\frac{d X}{d c}$ is large. A measurable effect could occur if an adsorption isotherm with low values of $\frac{d X}{d c}$ was used.

\section{Discussion of assumptions}

There is some evidence that the ability to absorb phosphate decreases with root age (Rovira and Bowen, 1968, Bowen, 1968). In contrast, radicles of onion and ryegrass have shown little change in the uptake rate of segments for up to 5 days (ryegrass) and 16 days (onion) (Drew and Nye, 1970). Furthermore, microbial activity in the rhizosphere (Rovira and Bowen, 1968), and especially the infection of roots by mycorrhizas (Bowen, 1968), can increase uptake rates and may make intake by older roots significant. Thus the validity of the function relating $V_{m}$ to root age is open to question and needs further testing. Even if the assumption is incorrect, however, the conclusions related to the effects of the other variables on phosphate uptake are the same.

Another, possibly more serious, shortcoming of the model is that it does not include known effects of other ions such as $\mathrm{Ca}^{++}$on the uptake rate of phosphate (Robson et al., 1970), or on the adsorption of phosphate by soils (Jensen, 1970, Barrow, 1972, Helyar et al., 1975). In many soils calcium should concentrate at the root surface with time (Oliver and Barber, 1966). The effect of calcium on diffusion could be taken into account by including its effect on the adsorption isotherm. The increased calcium concentration could cause increases in phosphate uptake rate by the plant and decreases in the solution phosphate level due to adsorption by the soil. The net effect is not obvious and would vary with species (Robson et al., 1970) and soil mineralogy.

Two assumptions of the model associated with transpiration are that the diffusion coefficient $\left(D_{p}\right)$ is unaffected by hydrodynamic dispersion, and that the moisture content of the soil is constant for different values of $r$. For a transpiration rate of $0.0025 \mathrm{ml}$ (cm root) ${ }^{-1}$ $\mathrm{hr}^{-1}$ the velocity of the water at $a=0.015$ $\mathrm{cm}$ and for $\theta=0.2$, is given by 


$$
V^{\prime}=\frac{W}{2 \pi a \theta}=0.133 \mathrm{~cm} \mathrm{hr}^{-1}\left(2.2 \times 10^{-3} \mathrm{~cm} \mathrm{~min}^{-1}\right) .
$$

Thus even at the root surface it appears that dispersion would not be a factor if the dispersion coefficient relates to porewater velocity for phosphate as it does for chloride (Kirda et al., 1973), and if the above value of $W$ is near maximum. However, this value was determined assuming the whole root system to be absorbing water. If in fact the waterabsorption rate differs for different roots or portions of roots, the pore-water velocity at the root surface may be large enough to cause dispersion in some cases.

The assumption of a constant moisture content with a change in $r_{m}$ may be one of the weakest assumptions in the model. Moisture gradients within $0.1 \mathrm{~cm}$ of the root are difficult or impossible to measure. Simulation studies, however, have indicated they may exist (Lambert and De Vries, 1969). Since $D_{p}$ strongly influences phosphate uptake and also depends on the soil moisture content (Olsen et al., 1965), then the current model could considerably overestimate phosphate uptake by not taking account of depletion of moisture near root. This difficulty could be overcome by linking the model to one such as that of Lambert and De Vries (1969), and making $D_{p}=f(\theta, t)$.

Up to this point the discussion has been about soil and plant factors which affect phosphate uptake per cm root. But a plant's total phosphate uptake from soil is strongly related to root length (Khasawneh and Copeland, 1973). Those factors which do not affect the ratio of root length to plant phosphate requirement are simple to account for, as they do not alter phosphate uptake rate per cm root needed to supply enough phosphate to the plant. Other factors such as soil structure, strength, and bulk density (Wiersum, 1962; Taylor and Gardiner, 1963) and phosphate status (Loneragan and Asher, 1967) may affect the root to top ratio, and the partitioning of phosphate between the roots and the tops. Thus the phosphate requirement ( $\mu$ moles (cm absorbing root) ${ }^{-1} \mathrm{hr}^{-1}$ ) will be changed. Furthermore, phosphate requirement per $\mathrm{cm}$ root may change with plant age. Interpretation of the output of the model depends on a knowledge of requirements for optimum growth in terms of average intake by roots growing at different rates.

Data on these factors are sparse, mainly because root lengths have been infrequently measured. Ideally, such data should permit calculation of relative root extension rates (RRER) analogous to the conventional familiar relative growth rate. This computation can be done with Loneragan and Asher's (1967) data for subterranean clover, after conversion from a weight basis to a length basis (see above). The RRER increased from $0.12 \mathrm{~cm} \mathrm{~cm}^{-1}$ $\mathrm{day}^{-1}$ for very phosphate-deficient plants to $0.15 \mathrm{~cm} \mathrm{~cm}^{-1}$ day $^{-1}$ for plants adequately supplied with phosphate. For the same treatments, the mean rate of phosphate intake over the 4-week period of the experiment, calculated according to Williams (1948), was respectively 0.000015 and $0.00044 \mu$ moles $\mathrm{cm}^{-1}$ $\mathrm{hr}^{-1}$. In our own experiments, subterranean clover, barrel medic, and alfalfa grown in soil for 4 weeks had mean RRER values of 0.1 (phosphate-deficient treatments), 0.2 (optimum phosphate levels), and less than $0.1 \mathrm{~cm} \mathrm{~cm}^{-1}$ day $^{-1}$ (marginally toxic treatments). The corresponding mean phosphate intake rates were $0.00013,0.0004$, and $0.0009 \mu$ moles $\mathrm{cm}^{-1} \mathrm{hr}^{-1}$.

From the above results for subterranean clover it appears that an average intake rate of $0.0004 \mu$ moles $\mathrm{cm}^{-1} \mathrm{hr}^{-1}$ is needed if the root growth rate is about 0.15 to $0.2 \mathrm{~cm} \mathrm{~cm}^{-1} \mathrm{hr}^{-1}$. In the simula- 
tions, calculated intake rates varied above and below this figure with time after absorption started (figs. 7, 9, 11). These results and further data will be discussed in a subsequent paper. The lack of information of this type is one major obstacle to understanding plantsoil relationships in general.

\section{ACKNOWLEDGMENTS}

We are grateful for the assistance of Peter Linz of the Mathematics Department, University of Califormia at Davis, and A. R. Gilmour, biometrician, New South Wales Department of Agriculture, and for a grant of computer funds from the National Science Foundation.

\section{LITERATURE CITED}

Amer, F., D. R. Bouldin, C. A. Black, and F. R. Duke

1955. Characterisation of soil phosphorus by anion exchange resin and $\mathrm{P}^{32}$ equilibration. Plant and Soil 6:391-408.

AsLYng, H. C.

1954. Lime and phosphate potentials of soils. Roy. Vet. Agric. Coll. Copenhagen, Yearb. 1-50.

BARBER, S. A.

1962. A diffusion and mass-flow concept of soil nutrient availability. Soil Sci. 93:39-49.

BARLEY, K. P.

1970. The configuration of the root system in relation to nutrient uptake. Adv. in Agron. 22:159-201.

BARROW, N. J.

1972. Influence of solution concentration of calcium on the adsorption of phosphate, sulfate, and molybdate by soils. Soil Sci. 113:175-345.

BAR-Yosef, B., E. BREsLER, and V. KAFKafi

1972. Uptake of phosphorus by plants growing under field conditions: II. Computed and experimental results for corn plants. Soil Sci. Soc. Amer. Proc. 36:789-94.

BeCKetT, P. T. H. and R. E. White

1964. Studies on the phosphate potentials of soils. Part III: The pool of labile inorganic phosphate. Plant and Soil 21:253-82.

BowEN, G. D.

1968. Phosphate uptake by mycorrhizas and uninfected roots of Pinus radiata in relation to root distribution. 9th Int. Congr. Soil Sci. II: 219-28.

BREwSTER, J. L., and P. B. H. TINKER

1972. Nutrient flow rates into roots. Soil and Fert. 35:355-59.

CRANK, J.

1956. The mathematics of diffusion. $347 \mathrm{pp}$. London: Oxford Univ. Press.

DEAN, L. A. and V. H. GLEDHILL

1956. Influence of soil moisture on phosphate adsorption as measured by an excised root technique. Soil Sci. 82:71-80.

Drew, M. C. and P H. NYE

1970. The supply of nutrient ions by diffusion to plant roots in soil. III. Uptake of phosphate by roots of onion, leek, and rye-grass. Plant and Soil 33:545-63.

EPSTEIN, E. and C. E. HAGEN

1952. A kinetic study of the absorption of alkali cations by barley roots. Plant Physiol. 27:457-74.

Fox, R. L. and E. J. KAMPRATH

1970. Phosphate sorption isotherms for evaluating the phosphate requirement of soil. Soil Sci. Soc. Amer. Proc. 34:902-06.

Frost, A. A. and K. G. Pearson

1961. Kinetics and mechanism. 2nd Ed. pp. 41-44. New York: John Wiley and Sons, Inc.

GuNARY, D.

1970. A new adsorption isotherm for phosphate in soils. J. Soil Sci. 21:72-77.

HELYAR, K. R. and A. L. BROWN

1975. Octan-l-ol extraction of molybdophosphoric acid in the colorimetric determination of ortho phosphate. (In preparation.) 
Helyar, K. R., Munns, D. N. and R. G. Burau

1975. Adsorption of phosphate by gibbsite. I. Effects of neutral chloride salts of calcium, Hsu, PA Ho magnesium, sodium and potassium. (In press-J. Soil Sci.)

1964. Adsorption of phosphate by aluminum and iron in soils. Soil Sci. Soc. Amer. Proc. 28:474-78.

JENSEN, H. E.

1970. The phosphate potential and phosphate capacity of soils. Plant and Soil 33:17-29.

1971. Phosphate solubility in Danish soils equilibrated with solutions of differing phosphate concentrations. J. Soil Sci. 22:261-66.

KAFkafi, U., A. M. Posner, and J. P. QUIRK

1967. Desorption of phosphate from kaolinite. Soil Sci. Soc. Amer. Soc. 31:348-53.

KaUtsky, J., K. P. Barley, and D. K. Fiddaman

1968. Ion uptake from soils by plant roots, subject to the Epstein-Hagen relation. Aust. J. Soil Res. 6:159-67.

KHASAWNEH, F. E. and JANE P. Copland

1973. Cotton root growth and uptake of nutrients: Relations of phosphorus uptake to quantity intensity and buffering capacity. Soil Sci. Soc. Amer. Proc, 37:250-54.

KIRDA, D., D. R. NIELSEN, and J. W. BigGAR

1973. Simultaneous transport of chloride and water during infiltration. Soil Sci. Soc. Amer. Proc. 37:339-45.

Lambert, J. R. and F. W. T. Penning De Vries

1969. Dynamics of water in the soil-plant-atmosphere system-a model named Troika. Proc. of Conf. on Applications of Continuous System Simulation. AFIPS Press, Montvale, N.J.

LARSEN, S.

1967. Soil phosphorus. Adv. in Agron. 19:151-209.

LEwIS, D. G. and J. P. QUIRK

1967. Phosphate diffusion in soil and uptake by plants. III: ${ }^{\text {s1 }}$-movement and uptake by plants as indicated by ${ }^{22} \mathrm{p}$-autoradiography. Plant and Soil. 27:445-53.

Lindsay, W. L. and E. C. Moreno

1960. Phosphate phase equilibria in soils. Soil Sci. Soc. Amer. Proc. 24:117-82.

LONERAGAN, J. F. and C. J. AsHeR

1967. Response of plants to phosphate concentration in solution culture. II. Rate of phosphate adsorption and its relation to growth. Soil Sci. 103:311-18.

Low, P. F. and C. A. BLACK

1950. Reactions of phosphate with kaolinite. Soil Sci. 70:273-90.

Murrman, R. P. and M. PeEch

1968. Reaction products of applied phosphate in limed soils. Soil Sci. Soc. Amer. Proc. 32: 493-96.

Nye, P. H.

1966. The effect of the nutrient intensity and buffering power of a soil, and the absorbing power, size and root hairs of a root, on nutrient absorption by diffusion. Plant and Soil 25:81-105.

Obihara, C. H. and E. W. Russell

1972. Specific adsorption of silicate and phosphate by soils. J. Soil Sci. 23:105-17.

OLIVER, S. and S. A. BARBER

1966. An evaluation of the mechanisms governing the supply of $\mathrm{Ca}, \mathrm{Mg}$, and $\mathrm{Na}$ to soybean roots. Soil Sci. Soc. Amer. Proc. 30:82-86.

OLSEN, S. R. and W. D. KEMPER

1967. Movement of nutrients to plant roots. Adv. in Agron. 20:91-151.

OLSEN, S. R., W. D. KEMPER, and J. V. VAN SchaIK

1965. Self-diffusion coefficients of phosphorus in soil measured by transient and steady-state methods. Soil Sci. Soc. Amer. Proc. 29:154-58.

Olsen, S. R., F. S. Watanabe, and R. E. Danielsen

1961. Phosphorus absorption by corn roots as affected by moisture and phosphorus concentration. Soil Sci. Soc. Amer. Proc. 25:289-94.

Ozanne, P. G. and T. C. Shaw

1967. Phosphate sorption by soils as a measure of the phosphate requirement for pasture growth. Aust. J. Agric. Res. 18:601-12.

PAssioura, J. B.

1963. A mathematical model for the uptake of ions from the soil solution. Plant and Soil 18:225-38. 
Probert, M. E.

1972. The dependence of isotopically exchangeable phosphate (L-value) on phosphate uptake. Plant and Soil 36:141-148.

Probert, M. E. and S. LARSEN

1972. The kinetics of heterogeneous isotopic exchange. J. Soil Sci. 23:76-81.

RICHMEYER, R. D.

1957. Different methods for initial value problems. New York Interscience Publisher Inc. p. 189.

Robson, A. D., D. G. EDWARDS, and J. F. LONERAGAN

1970. Calcium stimulation of phosphate absorption by annual legumes. Aust. J. Agric. Res. 21:601-12.

Rovira, A. D. and G. D. Bowen

1968. Anion uptake by plant roots: Distribution of anions and effects of micro-organisms. 9th Int. Congr. Soil Sci. II:209-17.

Swenson, R. M., C. V. Cole, and D. H. Sieling

1949. Fixation of phosphate by iron and aluminum and repacement by organic and inorganic ions. Soil Science. 67:3-22.

TAYLOR, H. M. and H. R. GARDINER

1963. Penetration of cotton seedling tap roots as influenced by bulk density, moisture content, and strength of soil. Soil Sci. $96: 153-56$.

WIERSUM, L. $\mathrm{K}$.

1962. Uptake of nitrogen and phosphorus in relation to soil structure and nutrient mobility. Plant and Soil 16:62-70.

WiLliams, E. G.

1962. Chemical soil tests as an aid to increased productivity. Intern Soil Conf. New Zealand, 820-34.

WILLIAMs, R. F.

1948. Effects of phosphate supply on rates of intake of phosphorus and nitrogen in gramineous plants. Aust. J. Scient. Res. Series B. 1:333-61.

Wilson, A. T.

1968. The chemistry underlying the phosphate problem in agriculture. Aust. J. Sci. 31:55-61. 


\section{Appendix 1}

The diffusion and convection of an ion on cylindrical coordinates in a porous medium to unit length of cylinder can be described by the following representaof Fick's first law of diffusion. The meaning of the symbols has been defined previously (pages 104-5).

$$
\frac{\partial q}{\partial t}=2 \pi r D p \frac{(\partial C)}{(\partial r)}+W C
$$

If $D_{p}$ is considered to be constant while $r, C, W, v$, and $q$ are allowed to vary, and if $v=W / 2 \pi r$, then,

$$
\begin{aligned}
& \frac{\partial q}{\partial t}=2 \pi D p \frac{\partial}{\partial r}\left(r \frac{\partial c)}{\partial r}-\frac{\partial}{\partial r}(v 2 \pi r C)\right. \\
& \frac{\partial q}{\partial t}=2 \pi D p\left\{\frac{\partial^{2} C}{\partial r^{2}}+\frac{\partial C}{\partial r}\right\}-2 \pi r \frac{\partial}{\partial r}(v C)-2 \pi v C
\end{aligned}
$$

Then dividing both sides by $2 \pi r$ to convert the units to a unit volume basis,

$$
\begin{aligned}
& \frac{(\partial \theta C)}{\partial t}=D p\left\{\frac{\partial^{2} C}{\partial r^{2}}+\frac{1}{r} \frac{\partial C}{\partial r}\right\}-\frac{\partial}{\partial r}(v C)-\frac{v C}{r} \\
& \text { Since } \frac{\partial \theta}{\partial t}=-\frac{\partial v}{\partial r}-\frac{v}{r}, \text { then, } \\
& \frac{\theta \partial C}{\partial t}=D p\left\{\frac{\partial^{2} C}{\partial r^{2}}+\frac{1}{r} \frac{\partial C}{\partial r}\right\}-\frac{v \partial C}{\partial r} \\
& \frac{\theta \partial C}{\partial t}=D p\left\{\frac{\partial^{2} C}{\partial r^{2}}+\left(1-\frac{W}{2 \pi D p}\right) \frac{1}{r} \frac{\partial C}{\partial r}\right\}
\end{aligned}
$$

For a similar derivation but allowing $D p$ to vary.

$$
\frac{\theta \partial C}{\partial t}=D p\left\{\frac{\partial^{2} C}{\partial r^{2}}+\left(1-\frac{W}{2 \pi D p}\right) \frac{1}{r} \frac{\partial C}{\partial r}\right\}+\frac{\partial C}{\partial r} \frac{\partial D p}{\partial r}
$$

In the case of the phosphate diffusing through soil the total diffusable phosphate is not all in solution so that effect of adsorption must be taken into account. Where $x$ represents the adsorbed phosphate ( $\mu$ moles $/ \mathrm{cm}^{3}$ soil) in equilibrium with solution phosphate, then the analogue of equation (6) is,

$$
\frac{\theta \partial C}{\partial t}=D p\left\{\frac{\partial^{2} C}{\partial r^{2}}+\left(1-\frac{W}{2 \pi D p} \frac{1}{r} \frac{\partial C}{\partial r}\right\}-\frac{\partial X}{\partial t}\right.
$$

The relationship between the solution concentration and adsorbed phosphate has been described by the Gunary adsorption isotherm (Gunary, 1970):

$$
X=C /(C B+A+D \sqrt{C})
$$


This equation can be differentiated with respect to $C$,

$$
b=\frac{\partial X}{\partial C}=(2 A+D \sqrt{C}) / 2(C B+A+D \sqrt{C})^{2}
$$

where $b$ is the slope of the adsorption isotherm at a given concentration $C$. Thus equation (8) can be expressed in the form

$$
\frac{\theta \partial C}{\partial t}=D p\left\{\frac{\partial^{2} C}{\partial r^{2}}+\left(1-\frac{W}{2 \pi D p}\right) \frac{1}{r} \frac{\partial C}{\partial r}\right\} \frac{\partial X}{\partial C} \frac{\partial C}{\partial t}
$$

Then, substituting $b$ for $\frac{\partial X}{\partial C},(11)$ can be simplified to,

$$
\frac{\partial C}{\partial t}=\frac{D p}{(b+\theta)}\left\{\frac{\partial^{2} C}{\partial r^{2}}+\left(1-\frac{W}{2 \pi D p}\right) \frac{1}{r} \frac{\partial C}{\partial r}\right\}
$$

The form analogous to equation (7) is,

$$
\frac{\partial C}{\partial t}=\frac{D p}{(b+\theta)}\left\{\frac{\partial^{2} C}{\partial r^{2}}+\left(1-\frac{W}{2 \pi D p}\right) \frac{1}{r} \frac{\partial C}{\partial r}\right\}+\frac{\partial C}{\partial r} \frac{\partial D p}{\partial r}
$$

\section{Appendix 2}

Glossary:

\section{Abbreviated listing of CSMP Program}
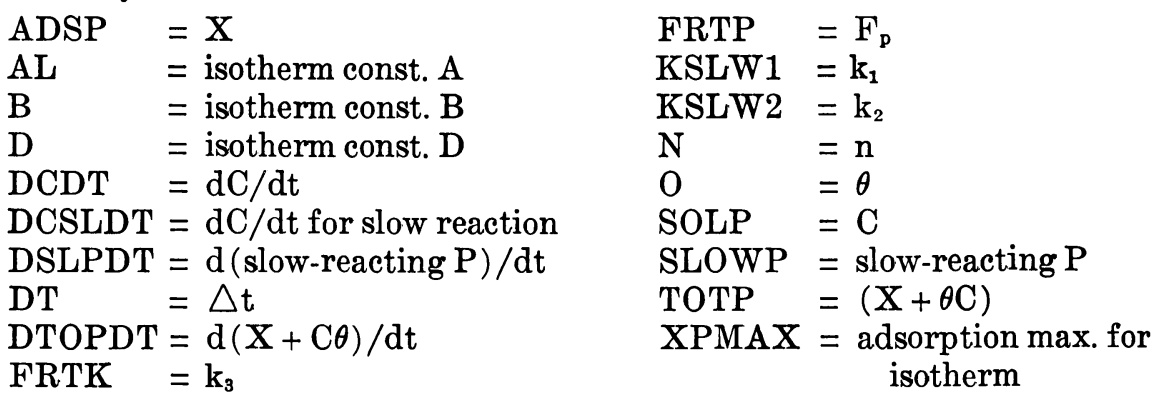

INITIAL

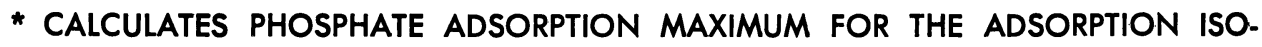
THERM NOSORT

CATXMX $=4 * A L * * 2 / D * * 2$

XPMAX $=$ CATXMX $/(C A T X M X * B+A L+C A T X M X * * 0.5 * D)$

$X P M A X B=1 / B$

IF(XPMAX.LT.XPMAXB)XPMAX = XPMAXB

* CHECKS FOR ROOT OF QUADRATIC TO USE, USING 10 UM P CONCENTRATION $U=A L^{* * 2}$

$X P=0.01 /(0.01 * B+A L+0.01 * * 0.5 * D)$ 


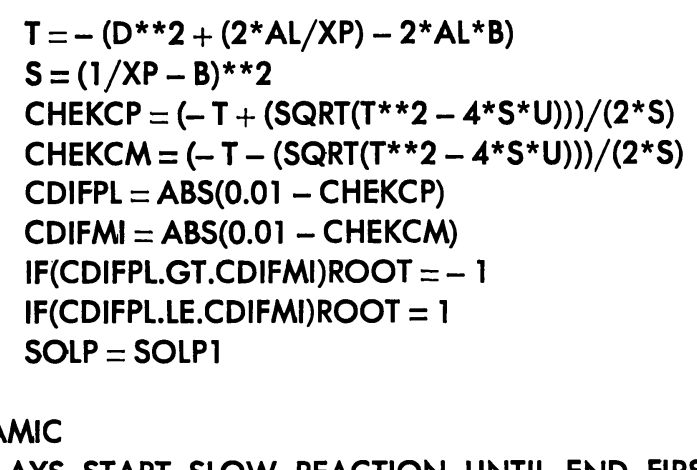

DYNAMIC

* DELAYS START SLOW REACTION UNTIL END FIRST DAY TO ACCOUNT FOR

* FACT THAT THE ADSORPTION ISOTHERM AND CO FOR SLOW REACTION

* DETERMINED AT 24 hOURS.

NOSORT

IF(TIME.LT.24)KSLWI $=0$

IF(TIME.GE.24)KSLW1 $=0.000572$

SORT

* FERTILIZER PHOSPHATE (FRTP) FLUXES

FRTP $=$ INTGRL(FRTP1.DFRPDT)

DFRPDT $=-$ FRTK $*$ FRTP

* SLOW REACTING PHOSPHATE (SLOWP) FLUXES

SLOWP $=$ INTGRL(SLOWPI,DSLPDT)

DCSLDT $=-(K S L W 1 *(S O L P * N))$

$A D S P I=S O L P /(S O L P * B+A L+S O L P * 0.5 * D)$

$S O L P P=S O L P+D C S L D T$

$A D S P 2=S O L P P /(S O L P P * B+A L+S O L P P * * 0.5 * D)$

DSLPDT $=\left(-\right.$ DCSLDT $\left.^{*} O\right)+($ ADSP1 - ADSP2 $)$

* ADSORBED RAPIDLY REACTING PHOSPHATE (ADSP) FLUXES

TOTP = INTGRL(TOTPI,DTOPDT)

DTOPDT = - DFRPDT - DSLPDT

* SOIL SOLUTION PHOSPHATE FLUXES , EQUILIB. ADSP. .

NOSORT

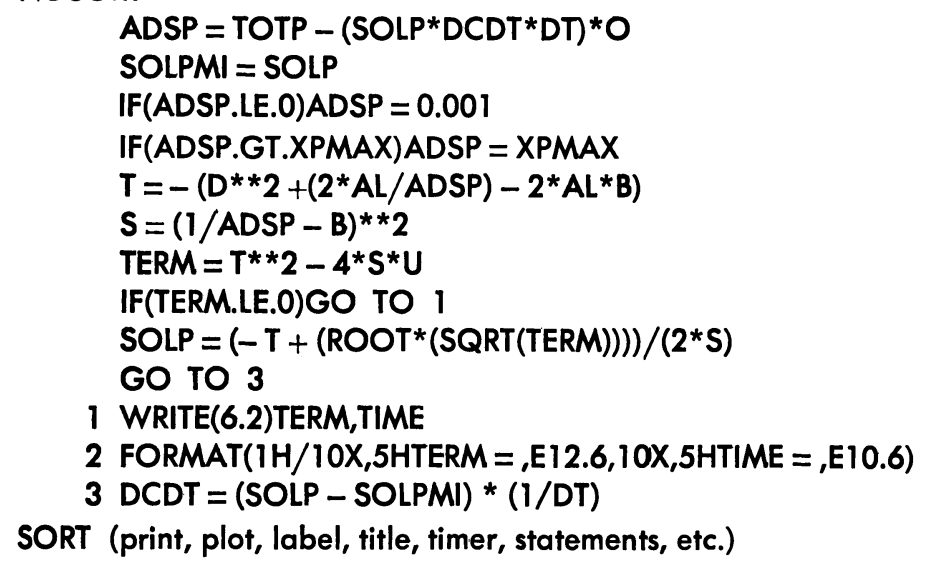

1 WRITE(6.2)TERM,TIME

2 FORMAT(1H/10X,5HTERM = ,E12.6,10X,5HTIME = ,E10.6)

3 DCDT $=($ SOLP - SOLPMI $)$ * (1/DT)

SORT (print, plot, label, title, timer, statements, etc.) 


\section{Appendix 3}

\section{Abbreviated listing of Fortran program}

Listing omits control statements, format statements, iteration sontroller and data. glossary of primary variables:

\begin{tabular}{|c|c|c|}
\hline A & $=$ & $\mathbf{a}$ \\
\hline $\mathrm{AL}$ & $=$ & isotherm A \\
\hline B & $=$ & isotherm B \\
\hline BPLI & $=$ & stability criterion \\
\hline$C(I)$ & $=$ & $\mathrm{C}_{\mathrm{m}}$ \\
\hline CMI(I) & $=$ & $\mathrm{C}_{\mathrm{m}}^{-}$ \\
\hline CPL(I) & $=$ & $\mathrm{C}^{+}{ }_{\mathrm{m}}$ \\
\hline CPLDIF & $=$ & crit. precision for CPLE \\
\hline CPLE & $=$ & estimate of $\mathrm{C}^{+} \mathrm{m}$ \\
\hline $\operatorname{co}(1)$ & $=$ & $C_{0}$ on day 1 \\
\hline COE & $=$ & estim. $C_{0}$ at $r=0$ \\
\hline D & $=$ & isotherm D \\
\hline DAYS & $=$ & run duration \\
\hline DH & $=$ & $D p$ \\
\hline DPA & $=$ & $\mathrm{Dp} /(\mathrm{b}+\theta)$ \\
\hline DR & $=$ & $\Delta r$ \\
\hline DT & $=$ & $\triangle t$ \\
\hline DTB & $=$ & $\triangle t /(2 \triangle r)$ \\
\hline DXDC & $=$ & $d x / d C$ \\
\hline$E(1)$ & $=$ & transpiration on day 1 \\
\hline EUP & $=$ & estimated uptake \\
\hline
\end{tabular}

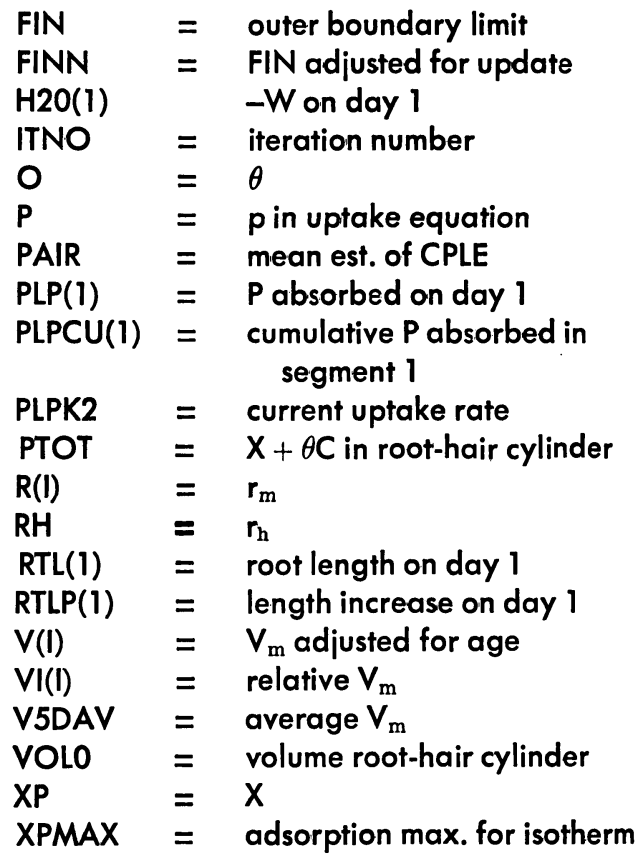

C SPECIFY INTEGERS AND DIMENSION ARRAYS (specify)

C SOIL MOISTURE, ADSORPTION ISOTHERM CONSTANTS, REL. VALUES VM 240 HR.

DATA $(\mathrm{VI}(\mathrm{J}), \mathrm{J}=1,240) /$

* $12 * 1.16,14 * 1.15,3 * 1.14,3 * 1.13,4 * 1.12,1.1$, (enter data)

C EXPT. LENGTH -DAYS,RAD. INCREMENT, ROOT HAIR LENGTH, ROOT RADIUS.

2 CONTINUE READ $(5,10)$ DAYS, DR, RH, A, P, DH, (O, D, B, AL, V5DAV) (enter data)

DO $7555 \mathrm{I}=1,100$

IF $(20-1) 7554$

$\operatorname{PLPCM}(\mathrm{I})=0$.

$7554 \operatorname{PLPCU}(\mathrm{I})=0$.

$\operatorname{PLP}(1+\mathrm{I})=0$.

$\operatorname{RTL}(I)=0$.

$7555 \mathrm{CO}(\mathrm{I})=0$.

C READ TRANSPIRATION $\times$ DAYS, ROOT LENGTH (RTL) $\times$ DAYS MEASURED,

C SOLUTION P CONCENTRATION $(C O) \times$ DAYS MEASURED. 
$\operatorname{READ}(5,11)(\mathrm{E}(1), \mathrm{I}=1, \mathrm{DAYS}), \operatorname{RTL}(12), \operatorname{RTL}(19), \operatorname{RTL}(28)$, $1 \mathrm{CO}(1), \mathrm{CO}(28)$

(enter data)

C VMAX FOR 5 DAY ROOTS, CALC. VMAX $\times$ HOURS FOR 10 DAYS.

DO $1 \mathrm{I}=1,240$

I $V(I)=V 1(I) * V 5 D A V$

C CONSTANTS FOR RUN, AND CALCULATIONS FROM THESE.

$\mathrm{U} 2=0$

$\mathrm{U}=\mathrm{AL} * * 2$

$\mathrm{TAL}=2 .{ }^{*} \mathrm{AL}$

$D 2=D * * 2$

$A 2=A * * 2$

LTH $=$ DAYS $* 24$

$621 \operatorname{PLP}(1)=0$

$M M=0.1 / D R$

$M M 1=M M+1$

$M M 2=M M-1$

$\mathrm{PRT}=\mathrm{MM} / 10+1$

$\mathrm{TDH}=2 .{ }^{\star} \mathrm{DH}$

$\mathrm{DH} 2=3.14 * \mathrm{TDH}$

C CALCULATES PHOSPHATE ADSORPTION MAXIMUM FOR ADSORPTION ISOTHERM.

CATXMX $=(T A L / D) * * 2$

XPMAX $=$ CATXMX $/($ CATXMX $* B+A L+T A L)$

$X P M A X B=1 . / B$

$X P M A X=A M A X I(X P M A X, X P M A X B)$

C CHECKS FOR ROOT QUADRATIC TO USE, USING 10 UM P CONCENTRATION $X P=.01 /(.01 * B+A L+.1 * D)$

$S=B-1 . / X P$

$T=T A L * S-D 2$

$S=S * S$

$S Q T=S Q R T\left(1 * * 2-4 .{ }^{*} S * U\right)$

DIV $=2 .{ }^{*} S$

CHEKCP $=(-T+S Q T) / D I V$

CHEKCM $=(-T-S Q T) / D I V$

CDIFPL = ABS(0.01 - CHEKCP)

$\mathrm{CDIFMI}=\mathrm{ABS}(0.01-\mathrm{CHEKCM})$

ROOT = SIGN(1.,CDIFMI - CDIFPL)

C CALCULATES AND WRITES RTL X DAYS (SQ. ROOT TRANSFORM), AND CO X DAYS

C (LOG TRANSFORM - LINEAR EXTRAPOLATION).

DO $340 I=1$, DAYS

IF(RTL (I).GT.0.)RTL(I) = SQRT(RTL(I))

340 IF(CO(I).GT,0.)CO(I) = ALOGIO(CO(I))

CALL INTTAB(RTL)

CALL INTTAB(CO)

DO 341 I = 1,DAYS

$\operatorname{RTL}(I)=\operatorname{RTL}(I) * * 2$

$C O(I)=\operatorname{EXP}((C O(I)-3) * 2.302585093$.

CS(I) $=$ SQRT $(C O(I))$ 


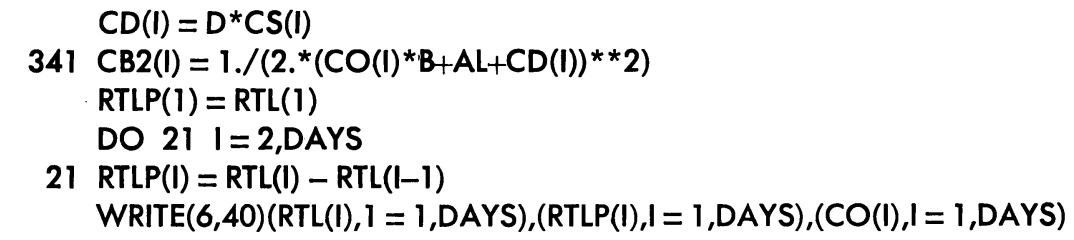

C VOLUME ROOT-HAIR CYLINDER, ASSIGN VALUES TO RADIUS INCREMENTS.

$R(1)=(A+R H)$
$D I F C O=D H 2 * R(1)$
$D O 33 \quad I=2,199$

$33 R(I)=R(I-1)+D R$

$\mathrm{VOLO}=3.14 *(R(1) * * 2-\mathrm{A} 2)$

$\mathrm{K}=0$

$\mathrm{JHR}=1$

C C START ROOT SEGMENT LOOP, ASSIGN INITIAL VALUES.

$80 \mathrm{KJI}=\mathrm{K}$

$K=K+1$

$P L P S=0$

IF(K.EQ.(DAYS + 1))GO TO 78

90 DO $100 \mathrm{I}=1,199$

$\mathrm{DCT}(\mathrm{I})=0$

$C(I)=C O(K)$

$100 \mathrm{CMI}(\mathrm{I})=\mathrm{C}(\mathrm{I})$

$\mathrm{CO}=\mathrm{CO}(\mathrm{K})$

$\mathrm{J}=0$

C START DAILY LOOP, CALCULATE DT.

$91 \mathrm{~J}=\mathrm{J}+1$

$K J 1=K J 1+1$

C INSERT IF STATEMENT, GO TO 15 FOR EXTRAPOLATION 6-10 DAYS,

C OR GO TO 264 AFTER NUMBER OF DAYS SIMULATION REQUIRED

IF(J.EQ.6)GO TO 15

$N=0$

TIME $=0$

TIME2 $=0$

$B P L 1=1 .+(T A L+C D(K J 1)) * C B 2(K J 1)$

$\mathrm{DT}=\mathrm{BBL}] * \mathrm{DR} * \mathrm{DR} / \mathrm{TDH}$

IDT $=D^{*} * 10000$

DT $=$ IDT $/ 10000$.

C WRITE PARAMETERS FOR DAY.

C CALCULATE INITIAL VALUES AND CONSTANTS FOR DAY.

ITNO $=24 / D T$

ITPHR $=I T N O / 24$

$\mathrm{DTB}=\mathrm{DT} /(2 * \mathrm{DR})$

DO $70 I=1,199$

IF(DCT(I)72,71,71

$71 \mathrm{C}(\mathrm{I})=\operatorname{AMINI}(\mathrm{C}(\mathrm{I}), \mathrm{CO}(\mathrm{KJ} \mathrm{I}))$

$\mathrm{CMI}(\mathrm{I})=\mathrm{AMINI}(\mathrm{CMI}(\mathrm{I}), \mathrm{CO}(\mathrm{KJ} \mathrm{I}))$

GO TO 70 
72 SUB $=C O(K J 1-1)-C O(K J 1)$

$C(I)=C(I)-S U B$

$\mathrm{CMI}(\mathrm{I})=\mathrm{CMI}(\mathrm{I})-\mathrm{SUB}$

70 CONTINUE

$\mathrm{H} 20=0$

WTM $=.5$

C START DT LOOP, CALCULATION INITIAL VALUES AND CONSTANTS FOR DT.

280 DO $301 \quad I=1,199$

$\operatorname{CPLE}(I)=2 * C(I)-\operatorname{CMI}(I)$

$301 \mathrm{CPL}(\mathrm{I})=\mathrm{CPLE}(\mathrm{I})$

PTOT $=\operatorname{VOLO}(C(1) *(O+1 . /(C(1) * B+A L+D * S Q R T(C(1)))))$

$W=-2$

$M=0$

C START ITERATION LOOP, CALCULATE P UPTAKE AND GRADIENT TO ROOT. $305 L=0$

$M=M+1$

IF(M.GT.20)GO TO 74

C CALCULATES C FOR ROOT-HAIR CYLINDER.

$\mathrm{COE}=(\mathrm{C}(1)+\mathrm{CPLE}(1)) / 2$.

$\mathrm{COE} 1=\mathrm{COE}^{*} 1000$

PLPKI $=\mathrm{V}(\mathrm{JHR}) * \mathrm{COE} 1 /(\mathrm{P}+\mathrm{COE} 1) * \mathrm{DT}$

$\operatorname{DCT}(1)=(C(2)+C P L E(2)-C(1)-C P L E(1)) /\left(2 .{ }^{*} D R\right)$

DIFCON $=(D C T(1) * D I F C O+H 2 O * C O E) * D T$

PTOTPL $=($ PTOT - PLPK1 + DIFCON $) /$ VOLO

$X P=(P T O T P L-C P L E(1) * O)$

IF(XP.LT.0.) XP $=.001$

$X P=A M I N I(X P, X P M A X)$

$S=B-1 . / X P$

$T=T A L * S-D 2$

$S=S * * 2$

$\operatorname{CPLE}(1)=\left(-T+\left(\operatorname{ROOT}^{*}\left(\operatorname{SQRT}\left(T * * 2-4 .{ }^{*} \mathrm{~S} * \mathrm{U}\right)\right)\right)\right) /\left(2 .{ }^{*} \mathrm{~S}\right)$

$W=W+1$

IF(W)600,601,602

600 CPLE $1=$ CPLE $(1)$

GO TO 603

601 CPLE2 $=\operatorname{CPLE}(1)$

GO TO 603

$602 W=-2$

$\operatorname{CPLE}(1)=($ CPLE $1+$ CPLE $2+\operatorname{CPLE}(1)) / 3$.

$603 \operatorname{CPLEAV}(1)=(\operatorname{CPLE}(1)+\operatorname{CPL}(1)) / 2$.

CPLDIF $=$ ABS(CPL(1) - CPLE(1))

IF(CPLDIF.GT.1E - 4)L $=\mathrm{L}+1$

IF(L.LT.1)GO TO 50

$51 \mathrm{CPL}(1)=\mathrm{CPLE}(1)$

C CALCULATES C(2) TO C99(CO).

DO $302 I=2,199$

$\mathrm{Cl}=(\mathrm{C}(\mathrm{I})+\mathrm{CPLE}(\mathrm{I})) / 2$.

IF $(C I . L T .0) C l=0.001$ 


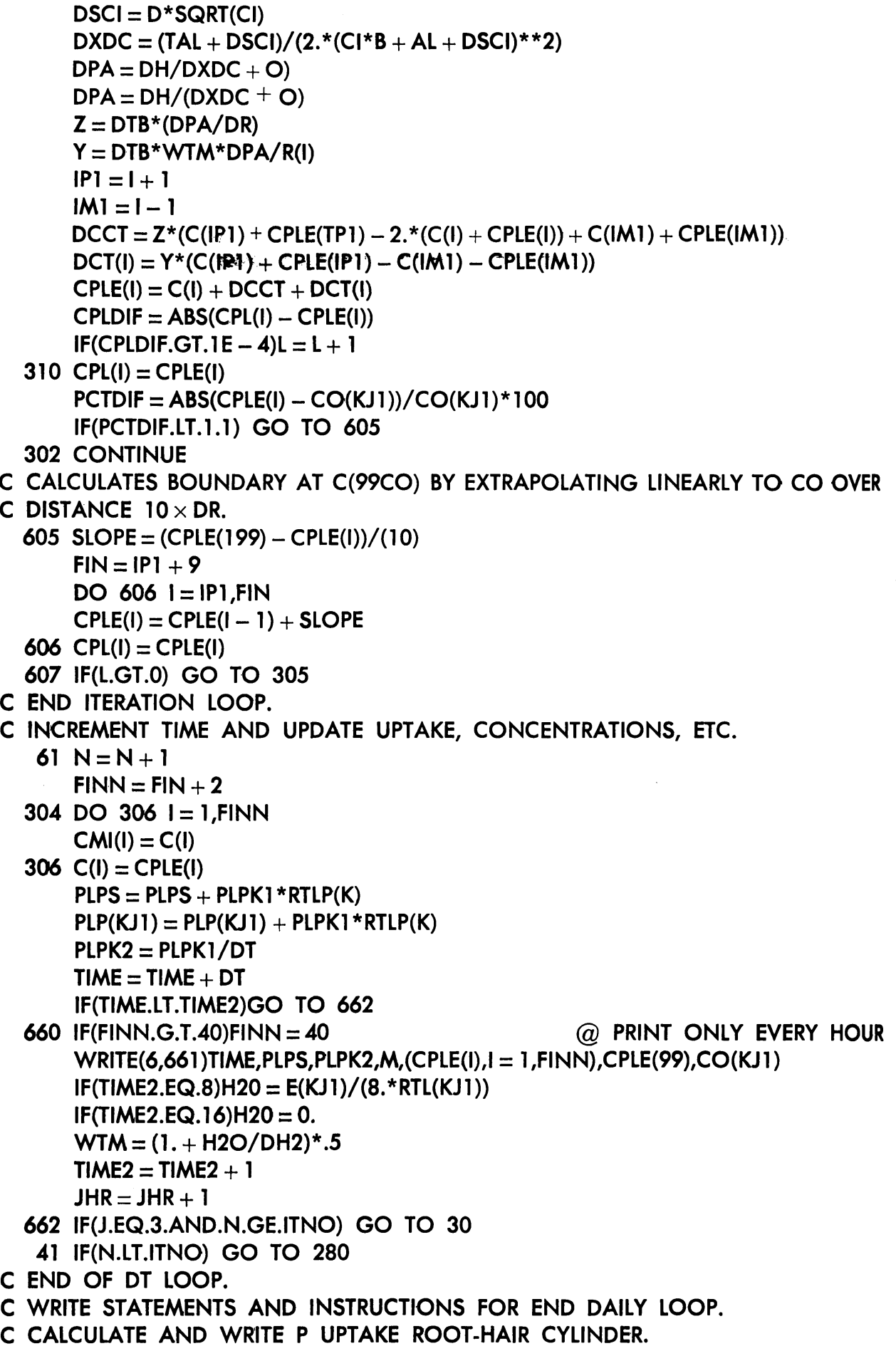




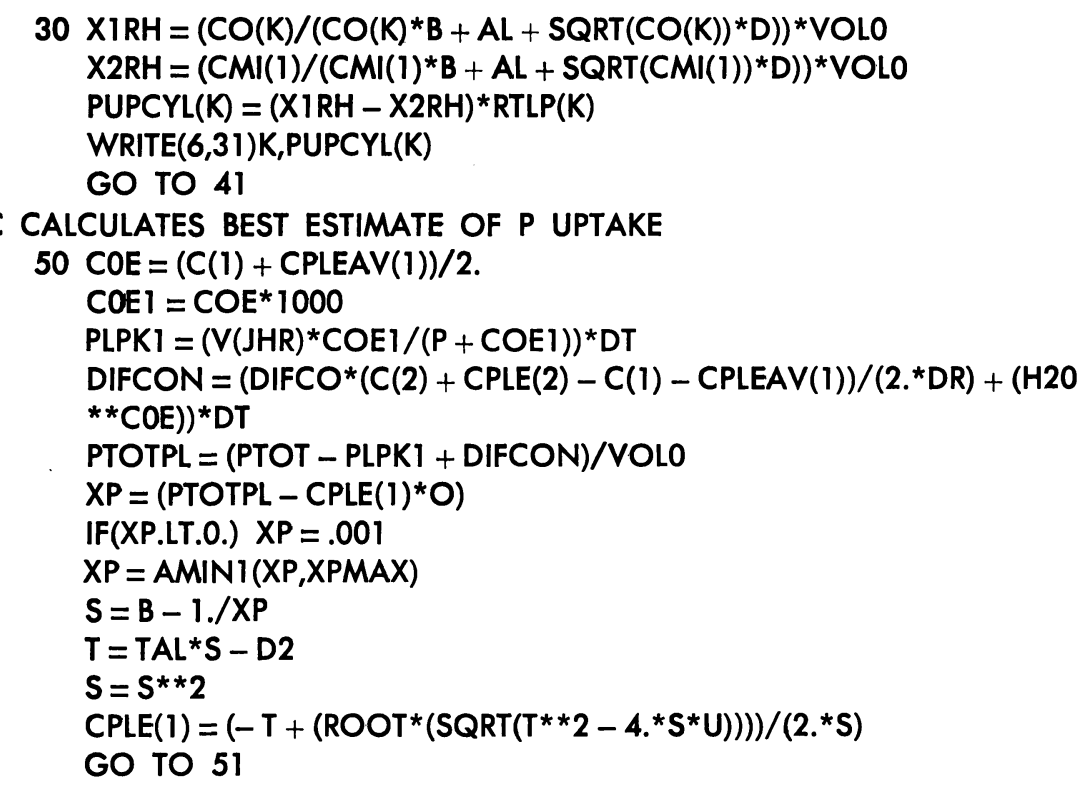

C EXTRAPOLATION OF P UPTAKE FOR DAYS 6 TO 10 THEN GOTO NEW ROOT

C SEGMENT OR END (INSERT GO TO 80 OR GO TO 78 RESPECTIVELY).

15 PLPS5 = PLPS

PLPS2 $=0$.

$M=$ DAYS $-K$

IF(M.LE.4)GO TO 80

$M=\operatorname{MINO}(M, 9)$

DO $16 I=5, M$

PLPEU $=$ EUP $(I) *$ PLPS5

PLPS $=$ PLPS5 + PLPEU

$\mathrm{L}=\mathrm{I}+1$

WRITE $(6,17)$ L, PLPS

$16 \operatorname{PLP}(K+1)=\operatorname{PLP}(K+1)+$ PLPEU

IF(M.EQ.5)GO TO 80

264 CODIF $=A B S(C O(1)-C O(D A Y S))$

IF(CODIF - .0001),,78

C CALCULATE P UPTAKE CUMULATIVE AND BY DAYS WHEN CO CONSTANT.

DO $263 \quad I=1,10$

263 PLPCM $(I)=$ PLP $(I) / R T L P(1)$

DO $265 K=2$,DAYS

DO $266 \mathrm{~J}=1,10$

$\mathrm{KJI}=\mathrm{K}+\mathrm{J}-1$

IF(KJI - DAYS),,265

$P L P(K J I)=P L P(K J I)+P L P C M(J) * R T L P(K)$

266 CONTINUE

265 CONTINUE

C WRITE P UPTAKE, CUMULATIVE AND BY DAYS.

$78 \operatorname{PLPCU}(1)=\operatorname{PLP}(1)$ 
DO $60 \mathrm{I}=2$,DAYS

$60 \operatorname{PLPCU}(I)=\operatorname{PLP}(I)+\operatorname{PLPCU}(I-1)$

WRITE(6,79)(PLP(I),I = I,DAYS),(PLPCU(I),I = I,DAYS)

77 STOP

END 
The journal HILGARDIA is published at irregular intervals, in volumes of about 650 to 700 pages. The number of issues per volume varies.

Single copies of any issue may be obtained free, as long as the supply lasts; please request by volume and issue number from:

\author{
PUBLICATIONS \\ UNIVERSITY OF CALIFORNIA \\ DIVISION OF AGRICULTURAL SCIENCES
}

1422 South 10th Street

Richmond, California 94804 
